\title{
Click Chemistry as a Macrocyclization Tool in the Solid Phase Synthesis of Small Cyclic Peptides
}

\author{
Rushia A. Turner, Allen G. Oliver, and R. Scott Lokey* \\ Department of Chemistry and Biochemistry, University of California at Santa Cruz, 1156 High \\ St., Santa Cruz, California, USA 95064
}

\section{Experimental Methods}

General: Fmoc-L-Leucine and 2-chlorotrityl chloride polystyrene resin were purchased from NovaBiochem and were used without further purification. Fmoc-L-Propargyl Glycine was purchased from Advanced Chemtech and used without further purification. All other reagents were purchased from Aldrich and used without further purification. Dichloromethane, acetonitrile, and methanol were purchased from EMD, N, N'-dimethylformamide was purchased from Acros, and all were used without purification unless noted.

Chromatography and Spectroscopic Measurements: A Thermo LCQ Classic ESI-MS coupled to an HP 1100 LC system with a photodiode array detector and a Sedex evaporative light scattering detector was used to determine the identity, purity and ratios of peptide products. Peptides were purified on a Shimadzu LC- 8A preparative HPLC system equipped with a Higgins Analytical C18 column, 250 x $20 \mathrm{~mm}$. NMR spectra were recorded in Fourier Transform mode on a Varian $600 \mathrm{MHz}$ magnetic resonance spectrophotometer. ${ }^{1} \mathrm{H}-\mathrm{NMR}$ spectra are reported as chemical shifts in parts per million ( $\mathrm{ppm}$ ) with the solvent resonance as the internal standard (DMSO- $\left.d_{6}: 2.5 \mathrm{ppm} ; \mathrm{CDCl}_{3}: 7.27 \mathrm{ppm}\right) .{ }^{13} \mathrm{C}-\mathrm{NMR}$ spectra are reported as chemical shifts in ppm with the solvent resonance as the internal standard $\left(\mathrm{CDCl}_{3}: 77.03 \mathrm{ppm}\right)$. Spin multiplicity is described by the following abbreviations: $\mathrm{s}=$ singlet, $\mathrm{d}=$ doublet, $\mathrm{t}=$ triplet, $\mathrm{q}=$ quartet, $\mathrm{m}=$ multiplet, $\mathrm{dd}=$ doublet of doublets, $\mathrm{dt}=$ doublet of triplets, and $\mathrm{br}=$ broad.

Abbreviations: DMF, N,N'-dimethylformamide; DIEA, diisopropyl ethyl amine; DCM, dichloromethane; HBTU, N,N,N',N'-Tetramethyl-O-(1H-benzotri-azol-1-yl)-uronium hexafluoro-phosphate; HOAt, 1-Hydroxy-7-Azabenzotriazole; DCC, dicyclohexyl carbodiimide; DVB, divinyl benzene; TFA, trifluoroacetic acid; LCMS, liquid chromatography mass spectrometry; PDA, photodiode array.

Loading Fmoc-L-Propargyl glycine onto 2-chlorotrityl chloride resin: $0.101 \mathrm{~g}$ of Fmoc-Lpropargyl glycine was dried under vacuum for 24 hours. 2-chlorotrityl chloride resin (200-400 mesh; 1\% DVB) was stored in a dessicator under vacuum prior to use. To the Fmoc-L-propargyl glycine was added $15 \mathrm{~mL}$ of dry dichloromethane and $55 \mu \mathrm{L}$ of dry DIEA (1.1 equivalents; stored over flame dried molecular sieves). This solution was transferred by syringe to a flame dried round bottom flask containing $2.51 \mathrm{~g}$ of resin and a stir bar. The resin and solution were 
stirred gently at room temperature for 3 hours, during which time the resin turned purplish-red in color. After 3 hours, the resin and solution were transferred to a polypropylene vial containing a fritted disk and fitted with a Teflon stopcock. The resin was drained and rinsed with DCM $(3 \times$ $30 \mathrm{~mL}), \operatorname{DMF}(3 \times 30 \mathrm{~mL})$, and again with DCM $(3 \times 30 \mathrm{~mL})$. The resin was dried thoroughly, and a $10 \mathrm{mg}$ aliquot was taken for use in determining the propargyl glycine loading value. The remaining resin was treated with a solution of DCM, methanol and DIEA (17:2:1 respectively, 2 $\times 30 \mathrm{~min}$.), in order to cap any unreacted resin.

Determination of resin loading by Fmoc cleavage: $10 \mathrm{mg}$ of resin was transferred to an eppendorf tube and allowed to swell in $800 \mu \mathrm{L}$ of DMF. After 15 minutes, $200 \mu \mathrm{L}$ of piperidine was added. The resin and solution were vortexed to effect good mixing, and allowed to sit for an additional 15 minutes. After the cleavage was complete, $100 \mu \mathrm{L}$ of the solution was transferred to a quartz cuvette, and diluted with $900 \mu \mathrm{L}$ of DMF. The absorbance measured at $\lambda=301 \mathrm{~nm}$ was 1.404. The piperidine-dibenzofulvene adduct that is formed upon Fmoc deprotection has a

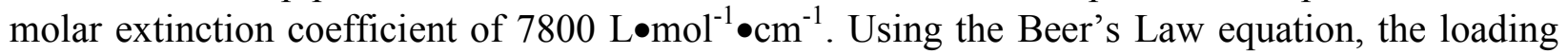
value was determined to be $0.18 \mathrm{mmol}$ of Fmoc-propargyl glycine per gram of resin.

Split synthesis of peptides: Generally, solid phase synthesis was carried out in $60 \mathrm{~mL}$ or $12 \mathrm{~mL}$ polypropylene filtration tubes equipped with a Teflon stopcock, in combination with a multiport vacuum manifold system to facilitate washes. All Fmoc deprotections were carried out by suspending the resin in a $20 \%$ piperidine/DMF solution, and agitating the tube at room temperature for 30 minutes. All amino acid couplings were performed by suspending the resin in a solution containing 4 equivalents of the Fmoc-amino acid, 4 equivalents of HBTU, and 6 equivalents of DIEA in minimal DMF. These couplings were monitored by the bromophenol blue test. ${ }^{2}$ The coupling of L-leucine azido acid was carried out under base-free conditions utilizing 3 equivalents of the azido acid, 3 equivalents of DCC, and 3 equivalents of HOAt in DMF. All coupling reactions were stirred at room temperature for one hour. After every reaction, the resin was washed thoroughly with DMF $(3 \times 10 \mathrm{~mL}), \mathrm{DCM}(3 \times 10 \mathrm{~mL})$ and again with DMF $(3 \times 10 \mathrm{~mL})$.

Split synthesis of the azide-terminated, linear tri-, tetra-, penta-, hexa-, and heptapeptides was carried out by first swelling $2.5 \mathrm{~g}$ of resin loaded with Fmoc-Lpropargyl glycine $(0.18 \mathrm{mmol} / \mathrm{g})$ in $30 \mathrm{~mL}$ of dichloromethane. Fmoc was cleaved and the deprotected propargyl glycine was coupled with Fmoc-L-leucine. The resin was washed and dried thoroughly. For the tripeptide, $1 / 5$ of the dry resin (by mass) was transferred to a separate filter tube. The remaining resin $(80 \%$ of the total mass) was Fmoc-deprotected and coupled with another amino acid. The second split involved the transfer of $1 / 4$ of this resin to another filter tube, which would become the tetrapeptide. Fmoc deprotection of the peptide on the remaining pool of resin $(60 \%$ of the total mass) was followed by amino acid coupling, and the third split in which $1 / 3$ of the dry mass of resin was transferred to a separate filter tube to become the pentapeptide. The remaining resin (40\% of total) was subject to Fmoc deprotection and amino acid coupling before being rinsed, dried, and divided in half. Half of this resin was reserved for the hexapeptide and the other half was put through Fmoc deprotection and amino acid coupling. With the final leucine amino acid added to the heptapeptide, the five pools of resin were each Fmoc-deprotected and coupled with L-azido leucine. Each pool of resin was washed thoroughly and a small sample ( $3 \mathrm{mg})$ of each was taken for cleavage from the resin (1\% TFA in DCM, 30 minutes) and analysis by LCMS. 
After verifying the purity of the linear tri-, tetra-, penta-, hexa-, and heptapeptide, copper mediated cyclization was carried out on each. $50 \mathrm{~mL}$ of DMF and $15 \mathrm{~mL}$ of acetonitrile were purged of molecular oxygen by bubbling with argon for 40 minutes. Each sample of linear peptide was swelled in $6.25 \mathrm{~mL}$ of purged DMF. DIEA and 2,6-lutidine were added to the resin volumetrically $(0.9 \mathrm{mmol} ; 10 \mathrm{eq}$ each). Sodium ascorbate was added as a 1\% solution in DMF (0.27 mmol, $3 \mathrm{eq})$. $\mathrm{CuBr}$ was dispensed last as a $1 \%$ solution in acetonitrile (90 $\mu \mathrm{mol} ; 1 \mathrm{eq})$. Each filter tube was bubbled with argon for one minute then sealed. The tubes were agitated on a rocking platform at room temperature for $6 \mathrm{~h}$. After $6 \mathrm{~h}$, each filter tube was drained and rinsed thoroughly $\left(3 \times \mathrm{H}_{2} \mathrm{O}, 3 \times\right.$ methanol, $\left.3 \times \mathrm{DMF}, 3 \times \mathrm{DCM}\right)$. The peptides were cleaved for one hour with TFA (10 mL of a $1 \%$ solution in DCM). Cleaved peptides were collected into scintillation vials and the TFA/DCM was evaporated with a stream of air. When all TFA was removed, the peptides were dissolved in methanol and a sample was taken for LCMS analysis.

All peptides were purified by reversed phase preparative HPLC, using acetonitrile/ water (with $0.1 \%$ TFA) as the eluent. All gradients ran between $95: 5: 0.01$ (water : acetonitrile : TFA) and $0: 100: 0.01$ (water : acetonitrile : TFA) for 60 minutes, with the UV detector set at $\lambda=198$ and $220 \mathrm{~nm}$ (Table S1).

\begin{tabular}{|c|c|c|c|}
\hline Compound & Elution Gradient $^{\mathrm{a}}$ & Mass isolated & \% yield \\
\hline $\mathbf{6}$ & $43-53 \%, 40 \mathrm{~min}$. & $0.010 \mathrm{~g}$ & $23 \%$ \\
\hline $\mathbf{7}$ & $43-53 \%, 40 \mathrm{~min}$. & $0.013 \mathrm{~g}$ & $25 \%$ \\
\hline $\mathbf{8}$ & $50-55 \%, 40 \mathrm{~min}$. & $0.017 \mathrm{~g}$ & $27 \%$ \\
\hline $\mathbf{9}$ & $50-55 \%, 40 \mathrm{~min}$. & $0.015 \mathrm{~g}$ & $20 \%$ \\
\hline $\mathbf{1 0}$ & $43-53 \%, 40 \mathrm{~min}$. & $0.025 \mathrm{~g}$ & $75 \%$ \\
\hline
\end{tabular}

Table S1. HPLC elution gradients and isolated yields for tetra-, penta-, hexa-, and heptapeptide cyclomonomers (compounds 6-9), and tripeptide cyclodimer (compound 10). ${ }^{\mathrm{a}_{0}} \%$ acetonitrile.

Determination of product ratios by integration of PDA peaks: Efficacy of the PDA detector as a method for determining monomer : dimer ratios was established by comparing the molar ratio of tetrapeptide cyclomonomer and cyclodimer products as determined by ${ }^{1} \mathrm{H}$ NMR to the ratio indicated by integration of the peaks in the PDA trace $(\lambda=220-240 \mathrm{~nm})$. Pure samples of the tetrapeptide cyclomonomer and cyclodimer were obtained and their ${ }^{1} \mathrm{H}$ NMR spectra were acquired (DMSO- $d_{6}$ ). These samples were then combined and the ${ }^{1} \mathrm{H}$ NMR spectrum of the mixture was acquired. Because the cyclodimer is $\mathrm{C} 2$-symmetric about the peptide backbone, each of the $\mathrm{C}_{\alpha}$ proton shifts observed integrates for two chemically equivalent protons. Distinct $\mathrm{C}_{\alpha}$ shifts from the cyclomonomer and cyclodimer were identified and integrated, resulting in a molar monomer : dimer ratio of $2.05: 1$. This mixture was then analyzed by LCMS to verify its purity and to generate a PDA trace. Because the triazole moiety is the only chromophore present in these cyclic peptides, the cyclodimer is expected to have absorbance twice that of the cyclomonomer. Taking this into account, the peaks in the PDA trace were integrated and the cyclomonomer : cyclodimer ratio was determined to be $2.07: 1$. The consistency between ratios established by ${ }^{1} \mathrm{H}$ NMR and by integration of PDA peaks was assumed to exist in the penta-, hexa-, and heptapeptides, and thus the integration of PDA peaks was used to determine the ratio of cyclomonomer : cyclodimer products in those peptides as well. 
O Synthesis of trifluoromethyl sulfonyl azide (triflyl azide): ${ }^{1}$ Sodium azide (5.7 g; $\left.\mathrm{F}_{3} \mathrm{C}-\mathrm{S}-\mathrm{N}_{3} 87.7 \mathrm{mmol}\right)$ was dissolved in distilled water $(14.4 \mathrm{~mL})$ with $\mathrm{CH}_{2} \mathrm{Cl}_{2}(24 \mathrm{~mL})$ and

O cooled on an ice bath. Triflyl anhydride $(5.0 \mathrm{~g} ; 17.7 \mathrm{mmol})$ was added slowly over five minutes. Stirring continued for 2.5 hours. The mixture was transferred to a separatory funnel and the $\mathrm{CH}_{2} \mathrm{Cl}_{2}$ layer was removed. The aqueous layer was extracted with $\mathrm{CH}_{2} \mathrm{Cl}_{2}(2 \times 12$ $\mathrm{mL}$ ). The organic fractions, containing the triflyl azide, were combined and washed once with saturated $\mathrm{Na}_{2} \mathrm{CO}_{3}$ and used without further purification.

o Synthesis of L-leucine azido acid by diazotransfer: L-Leucine ( $0.577 \mathrm{~g} ; 4.4 \mathrm{mmol})$ HO $\mathrm{N}_{3}$ was combined with $\mathrm{K}_{2} \mathrm{CO}_{3}(0.912 \mathrm{~g} ; 6.6 \mathrm{mmol}), \mathrm{CuSO}_{4}(0.007 \mathrm{~g} ; 44 \mu \mathrm{mol})$, deionized $\mathrm{H}_{2} \mathrm{O}(14 \mathrm{~mL})$, and $\mathrm{CH}_{3} \mathrm{OH}(28 \mathrm{~mL})$. The triflyl azide in DCM (24 mL; 8.8 mmol) was added and the mixture was stirred at room temperature for 24 hours. The organic solvents were evaporated in vacuo and the resultant slurry was diluted with $\mathrm{H}_{2} \mathrm{O}(50 \mathrm{~mL})$. This mixture was acidified to $\mathrm{pH} 6$ with concentrated $\mathrm{HCl}$ and diluted further with $50 \mathrm{~mL}$ of $0.25 \mathrm{M}$ phosphate buffer at $\mathrm{pH}$. The solution was extracted with ethyl acetate $(4 \times 50 \mathrm{~mL})$ to remove the sulfonamide byproduct. The aqueous phase was then acidified to $\mathrm{pH} 2$ with concentrated $\mathrm{HCl}$. The product was obtained from ethyl acetate extractions $(3 \times 75 \mathrm{~mL})$. The organic extracts were combined, dried with $\mathrm{MgSO}_{4}$, and evaporated to dryness yielding $0.470 \mathrm{~g}$. $(68 \%)$ of L-Leu azido acid as a pale yellow oil. ${ }^{1} \mathbf{H}$ NMR $\left(600 \mathrm{MHz}, \mathrm{CDCl}_{3}\right) \delta 3.89$ $(\mathrm{dd}, J=4.8,9 \mathrm{~Hz}, 1 \mathrm{H}), 1.86-1.82(\mathrm{~m}, 1 \mathrm{H}), 1.78-1.69(\mathrm{~m}, 2 \mathrm{H}) 1.0-0.97(2 \mathrm{~d}, J=6.6,6 \mathrm{H}) .{ }^{13} \mathrm{C}$ NMR $\left(600 \mathrm{MHz} ; \mathrm{CDCl}_{3}\right) \delta 177.4,60.0,39.8,25.0,22.8,21.4$.

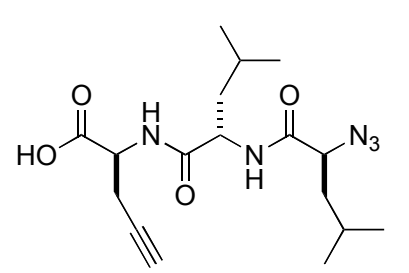

Data for linear tripeptide (1): ${ }^{\mathbf{1}} \mathbf{H}$ NMR $\left(600 \mathrm{MHz}\right.$; DMSO- $\left.d_{6}\right) \delta 8.40$ $(\mathrm{d}, J=8.4 \mathrm{~Hz}, 1 \mathrm{H}), 8.34(\mathrm{~d}, J=7.2 \mathrm{~Hz}, 1 \mathrm{H}), 4.46(\mathrm{dt}, J=6,9.6,15 \mathrm{~Hz}$, $1 \mathrm{H}), 4.34(\mathrm{dd}, J=7.2,13.2 \mathrm{~Hz}, 1 \mathrm{H}), 3.83(\mathrm{dd}, J=6.6,9 \mathrm{~Hz}, 1 \mathrm{H}), 2.89$ $(\mathrm{t}, J=2.4 \mathrm{~Hz}, 1 \mathrm{H}), 2.61(\mathrm{~m}, 2 \mathrm{H}), 1.64(\mathrm{~m}, 2 \mathrm{H}), 1.58(\mathrm{~m}, 2 \mathrm{H}), 1.50(\mathrm{~m}$, $2 \mathrm{H}), 0.95-0.88(\mathrm{~m}, 12 \mathrm{H})$. HRMS (ESI): Calculated for $\mathrm{C}_{17} \mathrm{H}_{27} \mathrm{~N}_{5} \mathrm{O}_{4}$ $\left(\mathrm{MH}^{+}\right)$: 366.2141. Found: 366.2143. IR: 3417, 3296, 3076, 2958, $2925,2853,2112,1643,1541,1466,1387,1371,1256,1207,1174$, and $1138 \mathrm{~cm}^{-1}$.

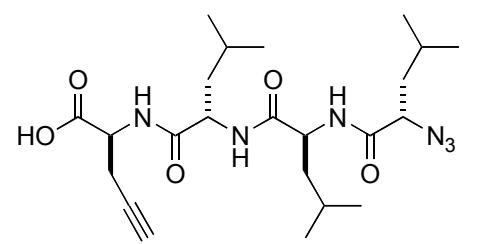

Data for linear tetrapeptide (2): ${ }^{1} \mathbf{H}$ NMR (600 MHz; DMSO- $\left.d_{6}\right) \delta$ $8.40(\mathrm{~d}, J=8.4 \mathrm{~Hz}, 1 \mathrm{H}), 8.12(\mathrm{~d}, J=8.4 \mathrm{~Hz}, 1 \mathrm{H}), 8.10(\mathrm{~d}, J=7.8$ $\mathrm{Hz}, 1 \mathrm{H}), 4.42(\mathrm{dt}, J=6,9,15 \mathrm{~Hz}, 1 \mathrm{H}), 4.38(\mathrm{dt}, J=6.6,9,15 \mathrm{~Hz}$, $1 \mathrm{H}), 4.33(\mathrm{dd}, J=5.4,6.6 \mathrm{~Hz}, 1 \mathrm{H}), 3.78(\mathrm{t}, J=7.8 \mathrm{~Hz}, 1 \mathrm{H}), 2.87(\mathrm{t}$, $J=3 \mathrm{~Hz}, 1 \mathrm{H}), 2.60(\mathrm{dt}, J=2.4,4.8,7.2 \mathrm{~Hz}, 2 \mathrm{H}), 1.60(\mathrm{~m}, 3 \mathrm{H}), 1.56$ $(\mathrm{m}, 2 \mathrm{H}), 1.47(\mathrm{~m}, 4 \mathrm{H}), 0.93-0.83(\mathrm{~m}, 18 \mathrm{H})$. HRMS (ESI): Calculated for $\mathrm{C}_{23} \mathrm{H}_{38} \mathrm{~N}_{6} \mathrm{O}_{5}\left(\mathrm{MH}^{+}\right)$: 479.2982. Found: 479.2983. IR: 3273, 3071, 2955, 2927, 2871, 2107, 1642, 1539, 1467, 1387, $1366,1278,1205$, and $1137 \mathrm{~cm}-1$.

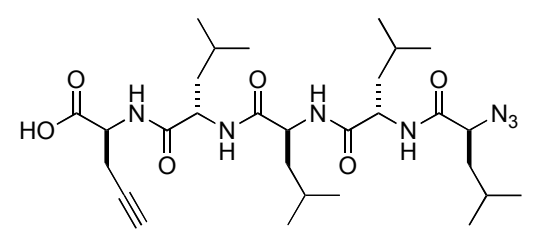

Data for linear pentapeptide (3): ${ }^{1}$ H NMR (600 MHz; DMSO- $\left.d_{6}\right)$ $\delta 8.40(\mathrm{~d}, J=8.4 \mathrm{~Hz}, 1 \mathrm{H}), 8.14(\mathrm{~d}, J=8.4 \mathrm{~Hz}, 1 \mathrm{H}), 8.10(\mathrm{~d}, J=$ $4.8 \mathrm{~Hz}, 1 \mathrm{H}), 7.89(\mathrm{~d}, J=8.4 \mathrm{~Hz}, 1 \mathrm{H}), 4.40-4.32(\mathrm{~m}, 4 \mathrm{H}), 3.79(\mathrm{t}$, $J=7.2 \mathrm{~Hz}, 1 \mathrm{H}), 2.85(\mathrm{br}, 1 \mathrm{H}), 2.61(\mathrm{dt}, J=3,6,8.4 \mathrm{~Hz}, 2 \mathrm{H})$, $1.62-1.53(\mathrm{~m}, 6 \mathrm{H}), 1.47-1.43(\mathrm{~m}, 6 \mathrm{H}), 0.92-0.83(\mathrm{~m}, 24 \mathrm{H})$. 
HRMS (ESI): Calculated for $\mathrm{C}_{29} \mathrm{H}_{49} \mathrm{~N}_{7} \mathrm{O}_{6}\left(\mathrm{MH}^{+}\right)$: 592.3823. Found: 592.3809. IR: 3429, 3307, 2961, 2928, 2873, 2113, 1676, 1646, 1542, 1469, 1438, 1389, 1370, 1208, 1182, and $1141 \mathrm{~cm}-1$.

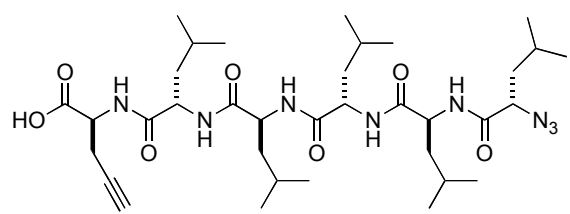

Data for linear hexapeptide (4): ${ }^{1} \mathbf{H}$ NMR (600 MHz; DMSO- $\left.d_{6}\right) \delta 8.39(\mathrm{~d}, J=8.4 \mathrm{~Hz}, 1 \mathrm{H}), 8.13(\mathrm{~d}, J=7.8 \mathrm{~Hz}$, $1 \mathrm{H}), 8.11(\mathrm{~d}, J=8.4 \mathrm{~Hz}, 1 \mathrm{H}), 7.91(\mathrm{~d}, J=8.4 \mathrm{~Hz}, 1 \mathrm{H}), 7.88$ $(\mathrm{d}, J=8.4 \mathrm{~Hz}, 1 \mathrm{H}), 4.43-4.28(\mathrm{~m}, 5 \mathrm{H}), 3.78(\mathrm{t}, J=7.2 \mathrm{~Hz}$, $1 \mathrm{H}), 2.87(\mathrm{t}, J=3 \mathrm{~Hz}, 1 \mathrm{H}), 2.60(\mathrm{dt}, J=3,6,8.4 \mathrm{~Hz}, 2 \mathrm{H})$, 1.61-1.53 (m, 7H), 1.46-1.41 (m, 8H), 0.93-0.82 (m, 30H). HRMS (ESI): Calculated for $\mathrm{C}_{35} \mathrm{H}_{60} \mathrm{~N}_{8} \mathrm{O}_{7}\left(\mathrm{MH}^{+}\right):$705.4663. Found: 705.4650. IR: 3423, 3281, 3082, 2959, 2923, 2868, $2109,1635,1543,1468,1437,1385,1366,1260,1207$, and $1171 \mathrm{~cm}-1$.

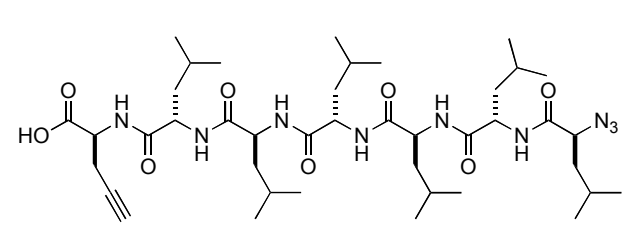

Data for linear heptapeptide (5): ${ }^{\mathbf{1}} \mathbf{H}$ NMR $(600 \mathrm{MHz}$; DMSO- $\left.d_{6}\right) \delta 8.39(\mathrm{~d}, J=8.4 \mathrm{~Hz}, 1 \mathrm{H}), 8.12(\mathrm{~d}, J=7.8 \mathrm{~Hz}$, $1 \mathrm{H}), 8.11(\mathrm{~d}, J=8.4 \mathrm{~Hz}, 1 \mathrm{H}), 7.91(\mathrm{~d}, J=8.4 \mathrm{~Hz}, 1 \mathrm{H})$, $7.87(\mathrm{~d}, J=8.4 \mathrm{~Hz}, 1 \mathrm{H}), 7.86(\mathrm{~d}, J=8.4 \mathrm{~Hz}, 1 \mathrm{H}), 4.38-$ $4.29(\mathrm{~m}, 6 \mathrm{H}), 3.77(\mathrm{t}, J=7.2,1 \mathrm{H}), 2.86(\mathrm{t}, J=2.4 \mathrm{~Hz}$, $1 \mathrm{H}), 2.59$ (dt, $J=3,6,8.4 \mathrm{~Hz}, 2 \mathrm{H}), 1.60-1.52(\mathrm{~m}, 8 \mathrm{H}), 1.46-1.40(\mathrm{~m}, 10 \mathrm{H}), 0.92-0.80(\mathrm{~m}, 36 \mathrm{H})$. HRMS (ESI): Calculated for $\mathrm{C}_{41} \mathrm{H}_{71} \mathrm{~N}_{9} \mathrm{O}_{8}\left(\mathrm{MH}^{+}\right)$: 818.5504. Found: 818.5503. IR: 3390, 3273, 3085, 2958, 2928, 2872, 2108, 1690, 1632, 1541, 1467, 1437, 1387, 1369, 1278, 1218, and 1170 $\mathrm{cm}-1$.

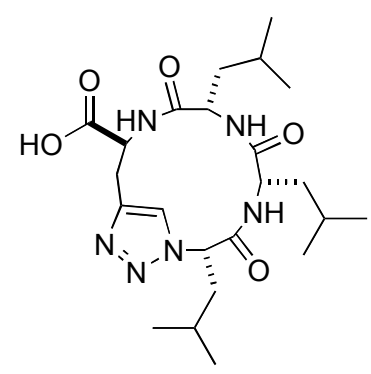

Data for tetrapeptide cyclomonomer (6): ${ }^{1} \mathbf{H}$ NMR (600 MHz; DMSO- $\left.d_{6}\right)$ $\delta 8.45(\mathrm{br}, 1 \mathrm{H}), 8.09(\mathrm{~d}, J=9.6 \mathrm{~Hz}, 1 \mathrm{H}), 7.6(\mathrm{~s}, 1 \mathrm{H}), 7.51(\mathrm{~d}, J=7.8 \mathrm{~Hz}$, $1 \mathrm{H}), 5.07(\mathrm{t}, J=7.8,1 \mathrm{H}), 4.64(\mathrm{~m}, 1 \mathrm{H}), 4.19(\mathrm{~m}, 2 \mathrm{H}), 3.28(\mathrm{dd}, J=4.2$, $15 \mathrm{~Hz}, 1 \mathrm{H}), 2.96(\mathrm{dd}, J=11.4,15 \mathrm{~Hz}, 1 \mathrm{H}), 2.26(\mathrm{~m}, 1 \mathrm{H}), 2.10(\mathrm{~m}, 2 \mathrm{H})$, $1.64(\mathrm{~m}, 1 \mathrm{H}), 1.52(\mathrm{~m}, 2 \mathrm{H}), 1.44(\mathrm{~m}, 2 \mathrm{H}), 1.27(\mathrm{~m}, 2 \mathrm{H}), 0.97(\mathrm{~d}, J=6.6$ $\mathrm{Hz}, 3 \mathrm{H}), 0.95$ (d, $J=6.6 \mathrm{~Hz}, 3 \mathrm{H}), 0.92(\mathrm{~d}, J=6.6 \mathrm{~Hz}, 3 \mathrm{H}), 0.85$ (d, $J=$ $6.6 \mathrm{~Hz}, 3 \mathrm{H})$. HRMS (ESI): Calculated for $\mathrm{C}_{23} \mathrm{H}_{38} \mathrm{~N}_{6} \mathrm{O}_{5}\left(\mathrm{MH}^{+}\right)$: 479.2982. Found: 479.2986. IR: 3412, 3071, 2956, 2928, 2868, 1722, $1665,1530,1467,1434,1388,1366,1325,1201,1174$, and $1141 \mathrm{~cm}-1$.

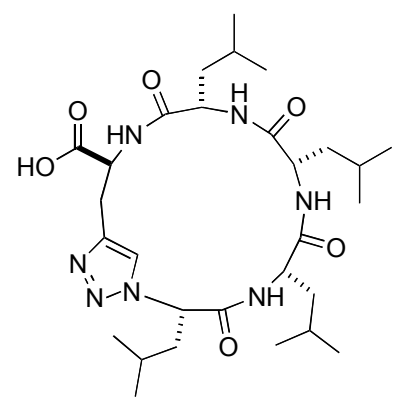

Data for pentapeptide cyclomonomer (7): ${ }^{1}$ H NMR (600 MHz; DMSO$\left.d_{6}\right) \delta 8.85(\mathrm{~d}, J=7.8,1 \mathrm{H}), 8.02(\mathrm{~d}, J=7.8 \mathrm{~Hz}, 1 \mathrm{H}), 7.9(\mathrm{~s}, 1 \mathrm{H}), 7.71(\mathrm{~d}$, $J=8.4 \mathrm{~Hz}, 1 \mathrm{H}), 7.40(\mathrm{~d}, J=7.8 \mathrm{~Hz}, 1 \mathrm{H}), 5.32(\mathrm{dd}, J=6,10.8 \mathrm{~Hz}, 1 \mathrm{H})$, $4.60(\mathrm{dt}, J=4.2,8.4,10.2 \mathrm{~Hz}, 1 \mathrm{H}), 4.14(\mathrm{dt}, J=5.4,7.8,9 \mathrm{~Hz}, 1 \mathrm{H})$, 3.97 (dt, $J=4.2,7.8,10.2 \mathrm{~Hz}, 1 \mathrm{H}), 3.80(\mathrm{dt}, J=4.2,7.2,10.2 \mathrm{~Hz}, 1 \mathrm{H})$, $3.17(\mathrm{dd}, J=4.2,15 \mathrm{~Hz}, 1 \mathrm{H}), 3.07$ (dd, $J=9.6,15 \mathrm{~Hz}, 1 \mathrm{H}), 2.17$ (m, $1 \mathrm{H}), 1.86-1.75(\mathrm{~m}, 3 \mathrm{H}), 1.64-1.50(\mathrm{~m}, 6 \mathrm{H}), 1.46-1.36(\mathrm{~m}, 2 \mathrm{H}), 0.93-$ $0.80(\mathrm{~m}, 24 \mathrm{H})$. HRMS (ESI): Calculated for $\mathrm{C}_{29} \mathrm{H}_{49} \mathrm{~N}_{7} \mathrm{O}_{6}\left(\mathrm{MH}^{+}\right)$: 592.3823. Found: 592.3816. IR: 3390, 3328, 3075, 2959, 2872, 1722, $1664,1530,1469,1437,1388,1330,1203,1176$, and $1138 \mathrm{~cm}-1$. 


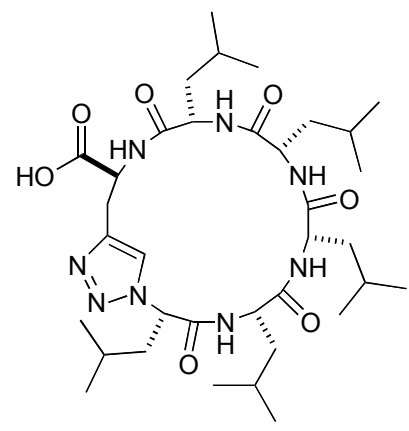

Data for hexapeptide cyclomonomer (8): ${ }^{1} \mathbf{H}$ NMR $(600 \mathrm{MHz}$; DMSO$\left.d_{6}\right) \delta 8.63(\mathrm{~d}, J=8.4 \mathrm{~Hz}, 1 \mathrm{H}), 8.53(\mathrm{~s}, 1 \mathrm{H}), 8.17(\mathrm{~d}, J=4.8,1 \mathrm{H}), 8.03$ (d, $J=8.4 \mathrm{~Hz}, 1 \mathrm{H}), 7.94(\mathrm{~d}, J=6.6 \mathrm{~Hz}, 1 \mathrm{H}), 6.94(\mathrm{~d}, J=8.4 \mathrm{~Hz}, 1 \mathrm{H})$, 5. $53(\mathrm{dd}, J=3.6,12 \mathrm{~Hz}, 1 \mathrm{H}), 4.46(\mathrm{dt}, J=3.6,11.4,14.4 \mathrm{~Hz}, 1 \mathrm{H})$, 4.21-4.14 (m, 2H), $4.02(\mathrm{~m}, 1 \mathrm{H}), 3.22(\mathrm{~d}, J=13.8 \mathrm{~Hz}, 1 \mathrm{H}), 3.05(\mathrm{dd}, J$ $=12,16.2 \mathrm{~Hz}, 1 \mathrm{H}), 2.15-2.09(\mathrm{~m}, 2 \mathrm{H}), 1.82(\mathrm{~m}, 1 \mathrm{H}), 1.71-1.33(\mathrm{~m}$, $12 \mathrm{H}), 0.95-0.83(\mathrm{~m}, 27 \mathrm{H}), 0.71(\mathrm{~d}, J=6.6,3 \mathrm{H})$. HRMS (ESI): Calculated for $\mathrm{C}_{35} \mathrm{H}_{60} \mathrm{~N}_{8} \mathrm{O}_{7}\left(\mathrm{MH}^{+}\right)$: 705.4663 . Found: 705.4652. IR: 3399, 2959, 2928, 2872, 1731, 1656, 1528, 1469, 1437, 1388, 1369, $1330,1261,1218,1171 \mathrm{~cm}-1$.

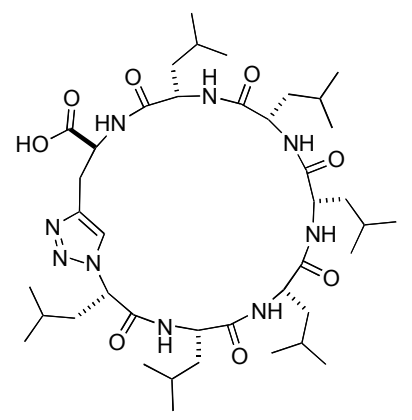

Data for heptapeptide cyclomonomer (9): ${ }^{1} \mathbf{H}$ NMR (600 MHz; DMSO$\left.d_{6}\right) \delta 8.37(\mathrm{br}, 1 \mathrm{H}), 7.99(\mathrm{br}, 1 \mathrm{H}), 7.95(\mathrm{br}, 1 \mathrm{H}) 7.91(\mathrm{~s}, 1 \mathrm{H}), 7.72(\mathrm{br}$, $1 \mathrm{H}), 7.57$ (br, 1H), 5.47 (dd, $J=4.8,10.8 \mathrm{~Hz}, 1 \mathrm{H}), 4.33(\mathrm{~m}, 2 \mathrm{H}), 4.23$ (br, 1H), $4.15(\mathrm{~m}, 1 \mathrm{H}), 3.96(\mathrm{br}, 2 \mathrm{H}), 3.93(\mathrm{~m}, 1 \mathrm{H}), 3.27$ (dd, $J=2.4,15$ $\mathrm{Hz}, 1 \mathrm{H}), 3.04(\mathrm{dd}, J=11.4,15 \mathrm{~Hz}, 1 \mathrm{H}), 2.07-2.05(\mathrm{~m}, 2 \mathrm{H}), 1.70-1.45$ $(\mathrm{m}, 14 \mathrm{H}), 1.00(\mathrm{~m}, 2 \mathrm{H}), 0.93-0.81(\mathrm{~m}, 33 \mathrm{H}), 0.78(\mathrm{~d}, J=6.6,3 \mathrm{H})$. HRMS (ESI): Calculated for $\mathrm{C}_{41} \mathrm{H}_{71} \mathrm{~N}_{9} \mathrm{O}_{8}\left(\mathrm{MH}^{+}\right)$: 818.5504. Found: 818.5486. IR: 3434, 3054, 2959, 2928, 2872, 1728, 1653, 1534, 1469, $1437,1388,1369,1327,1204$, and $1171 \mathrm{~cm}-1$.

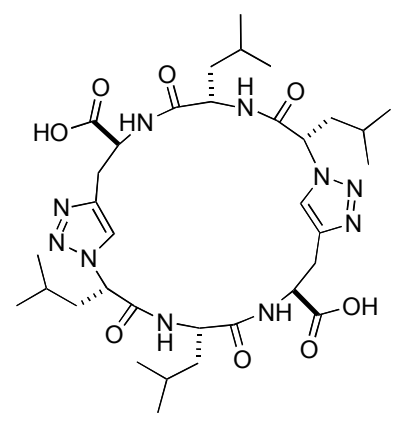

Data for tripeptide cyclodimer (10): ${ }^{1} \mathbf{H}$ NMR $\left(600 \mathrm{MHz}\right.$; DMSO- $\left.d_{6}\right) \delta$ $8.65(\mathrm{~d}, J=8.4 \mathrm{~Hz}, 2 \mathrm{H}), 8.63(\mathrm{~d}, J=4.8 \mathrm{~Hz}, 2 \mathrm{H}), 8.10(\mathrm{~s}, 2 \mathrm{H}), 5.47(\mathrm{dd}$, $J=4.8,11.4 \mathrm{~Hz}, 2 \mathrm{H}), 4.39(\mathrm{dt}, J=2.4,8.4,11.4 \mathrm{~Hz}, 2 \mathrm{H}), 4.19(\mathrm{~m}, 2 \mathrm{H})$, $3.26(\mathrm{dd}, J=1.8,16.2 \mathrm{~Hz}, 2 \mathrm{H}), 3.03(\mathrm{dd}, J=11.4,16.2 \mathrm{~Hz}, 2 \mathrm{H}), 2.03$ (dt, $J=7.2,9.6,11.4 \mathrm{~Hz}, 2 \mathrm{H}), 1.76-1.68(\mathrm{~m}, 4 \mathrm{H}), 1.52(\mathrm{~m}, 2 \mathrm{H}), 1.46$ $(\mathrm{m}, 2 \mathrm{H}), 1.01(\mathrm{~m}, 2 \mathrm{H}), 0.94(\mathrm{~d}, J=6.6,6 \mathrm{H}), 0.86(\mathrm{~d}, J=7.2,6 \mathrm{H}) 0.84$ (d, $J=7.2,6 \mathrm{H}), 0.753(\mathrm{~d}, J=6.6,6 \mathrm{H})$. HRMS (ESI): Calculated for $\mathrm{C}_{34} \mathrm{H}_{54} \mathrm{~N}_{10} \mathrm{O}_{8}\left(\mathrm{MH}^{+}\right)$: 731.4204. Found: 731.4207.

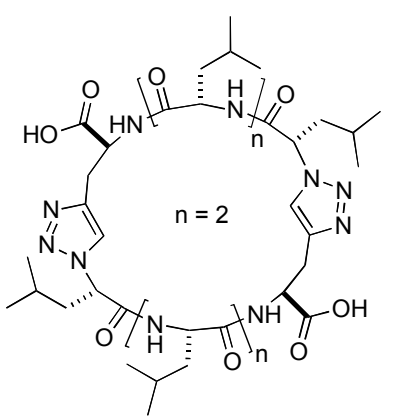

Data for tetrapeptide cyclodimer (11): ${ }^{1} \mathbf{H}$ NMR $\left(600 \mathrm{MHz}\right.$; DMSO- $\left.d_{6}\right) \delta$ $9.06(\mathrm{~d}, J=8.4 \mathrm{~Hz}, 2 \mathrm{H}), 7.7(\mathrm{~s}, 2 \mathrm{H}), 7.41(\mathrm{~d}, J=9 \mathrm{~Hz}, 1 \mathrm{H}), 7.14(\mathrm{~d}, J=$ $8.4 \mathrm{~Hz}, 2 \mathrm{H}), 5.43(\mathrm{dd}, J=4.8,11.4 \mathrm{~Hz}, 2 \mathrm{H}), 4.62(\mathrm{br}, 2 \mathrm{H}), 4.44(\mathrm{dt}, J=$ $4.2,9.6,13.8 \mathrm{~Hz}, 2 \mathrm{H}), 4.30$ (q, 2H), 3.25 (dd, $J=10.2,20.4 \mathrm{~Hz}, 2 \mathrm{H})$, $3.11(\mathrm{dd}, J=9,21.7 \mathrm{~Hz}, 1 \mathrm{H}), 1.90(\mathrm{~m}, 2 \mathrm{H}), 1.80(\mathrm{~m}, 2 \mathrm{H}), 1.66-1.53(\mathrm{~m}$, $8 \mathrm{H}), 1.30(\mathrm{~m}, 2 \mathrm{H}), 1.15(\mathrm{~m}, 4 \mathrm{H}), 0.97(\mathrm{~d}, J=6.6 \mathrm{~Hz}, 6 \mathrm{H}), 0.855(\mathrm{~d}, J=6$ $\mathrm{Hz}, 6 \mathrm{H}), 0.853(\mathrm{~d}, J=6.6 \mathrm{~Hz}, 6 \mathrm{H}), 0.83(\mathrm{~d}, J=6.6 \mathrm{~Hz}, 6 \mathrm{H}), 0.65$ (d, $J=$ $6.6 \mathrm{~Hz}, 6 \mathrm{H}), 0.42(\mathrm{~d}, J=6.6 \mathrm{~Hz}, 6 \mathrm{H})$. HRMS (ESI): Calculated for $\mathrm{C}_{46} \mathrm{H}_{76} \mathrm{~N}_{12} \mathrm{O}_{10}\left(\mathrm{MH}^{+}\right)$: 957.5886. Found: 957.5878. IR: 3427, 3326, $3066,2960,2928,2873,1731,1663,1546,1469,1439,1389,1369,1321,1291,1253,1206$, and $1140 \mathrm{~cm}-1$. 


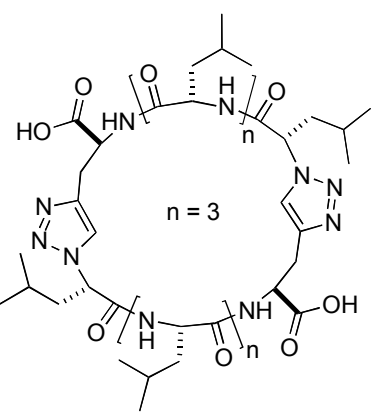

Data for pentapeptide cyclodimer (12): ${ }^{1} \mathbf{H}$ NMR (600 MHz; DMSO- $\left.d_{6}\right)$ $8.34(\mathrm{~d}, J=9 \mathrm{~Hz}, 2 \mathrm{H}), 8.04(\mathrm{br}, 2 \mathrm{H}), 7.73(\mathrm{~s}, 2 \mathrm{H}), 7.66(\mathrm{br}, 2 \mathrm{H}), 7.45$ $(\mathrm{d}, J=7.8 \mathrm{~Hz}, 2 \mathrm{H}), 5.30(\mathrm{~m}, 2 \mathrm{H}), 4.58(\mathrm{br}, 2 \mathrm{H}), 4.45$ (br, 2H), 4.43 (br, $2 \mathrm{H}), 4.31(\mathrm{br}, 2 \mathrm{H}), 2.07(\mathrm{~m}, 2 \mathrm{H}), 2.01(\mathrm{~m}, 2 \mathrm{H}), 1.65-1.41(\mathrm{~m}, 20 \mathrm{H})$, 0.91-0.79 (m, 48H). HRMS (ESI): Calculated for $\mathrm{C}_{58} \mathrm{H}_{98} \mathrm{~N}_{14} \mathrm{O}_{12}\left(\mathrm{MH}^{+}\right)$: 1183.7567. Found: 1183.7546.

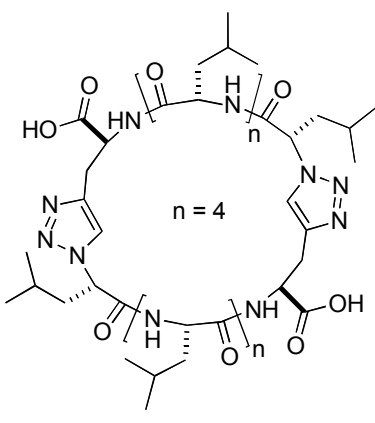

Data for hexapeptide cyclodimer (13): ${ }^{1} \mathbf{H}$ NMR $\left(600 \mathrm{MHz}\right.$; DMSO- $\left.d_{6}\right)$ $8.81(\mathrm{~d}, J=7.8 \mathrm{~Hz}, 2 \mathrm{H}), 8.60(\mathrm{~d}, J=8.4 \mathrm{~Hz}, 2 \mathrm{H}), 8.41(\mathrm{~d}, J=9 \mathrm{~Hz}$, $2 \mathrm{H}), 7.66(\mathrm{~s}, 2 \mathrm{H}), 7.47(\mathrm{~d}, J=8.4 \mathrm{~Hz}, 2 \mathrm{H}), 6.82(\mathrm{br}, 2 \mathrm{H}), 5.50(\mathrm{~m}, 2 \mathrm{H})$, $4.82(\mathrm{~m}, 2 \mathrm{H}), 4.68(\mathrm{~m}, 2 \mathrm{H}), 4.56(\mathrm{br}, 2 \mathrm{H}), 4.47(\mathrm{~m}, 2 \mathrm{H}), 4.42(\mathrm{~m}, 2 \mathrm{H})$, 2.91 (br, 2H), $2.76(\mathrm{br}, 2 \mathrm{H}), 1.89(\mathrm{~m}, 4 \mathrm{H}), 1.68(\mathrm{~m}, 4 \mathrm{H}), 1.60(\mathrm{~m}, 4 \mathrm{H})$, $1.51-1.39(\mathrm{~m}, 10 \mathrm{H}), 1.27$ (br, 4H), $1.12(\mathrm{br}, 4 \mathrm{H}), 0.90-0.72(\mathrm{~m}, 54 \mathrm{H})$, 0.46 (d, $J=5.4 \mathrm{~Hz}, 6 \mathrm{H})$. HRMS (ESI): Calculated for $\mathrm{C}_{70} \mathrm{H}_{120} \mathrm{~N}_{16} \mathrm{O}_{14}$ $\left(\mathrm{MH}^{+}\right)$: 1409.9248. Found: 1409.9225.

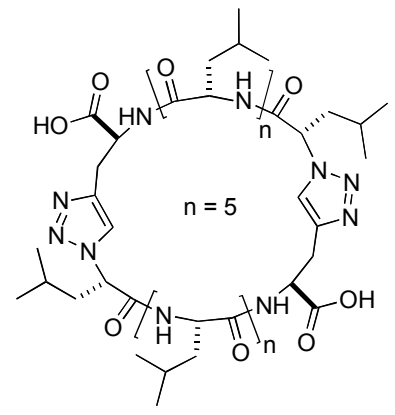

Data for heptapeptide cyclodimer (14): ${ }^{1} \mathbf{H}$ NMR $\left(600 \mathrm{MHz}\right.$; DMSO- $\left.d_{6}\right)$ $\delta$ 8.40-8.31 (br, 4H), 7.93 (br, 2H), $7.69(\mathrm{~s}, 2 \mathrm{H}), 7.52$ (br, 2H), 7.36 (br, $2 \mathrm{H}), 5.32(\mathrm{br}, 2 \mathrm{H}), 4.78(\mathrm{br}, 2 \mathrm{H}), 4.61$ (br, $4 \mathrm{H}), 4.48$ (br, 2H), 4.27 (br, 2H), 4.22 (br, 2H), 1.99 (br, 4H), 1.62-1.25 (m, 32H), 0.92-0.70 (m, $72 \mathrm{H})$. HRMS (ESI): Calculated for $\mathrm{C}_{82} \mathrm{H}_{142} \mathrm{~N}_{18} \mathrm{O}_{16}\left(\mathrm{MH}^{+}\right)$: 1636.0929 . Found: 1636.0935. 

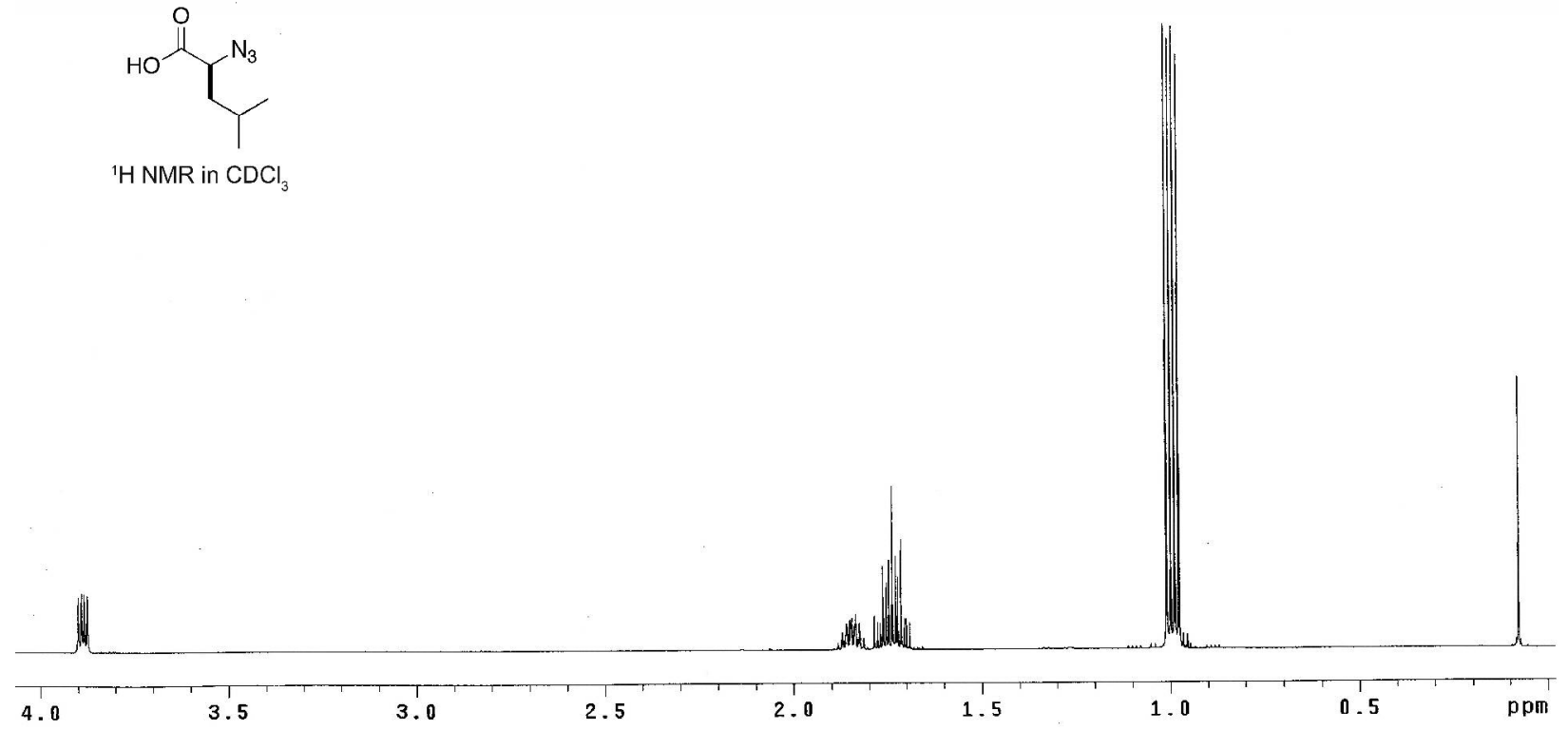
L-azido-Leu

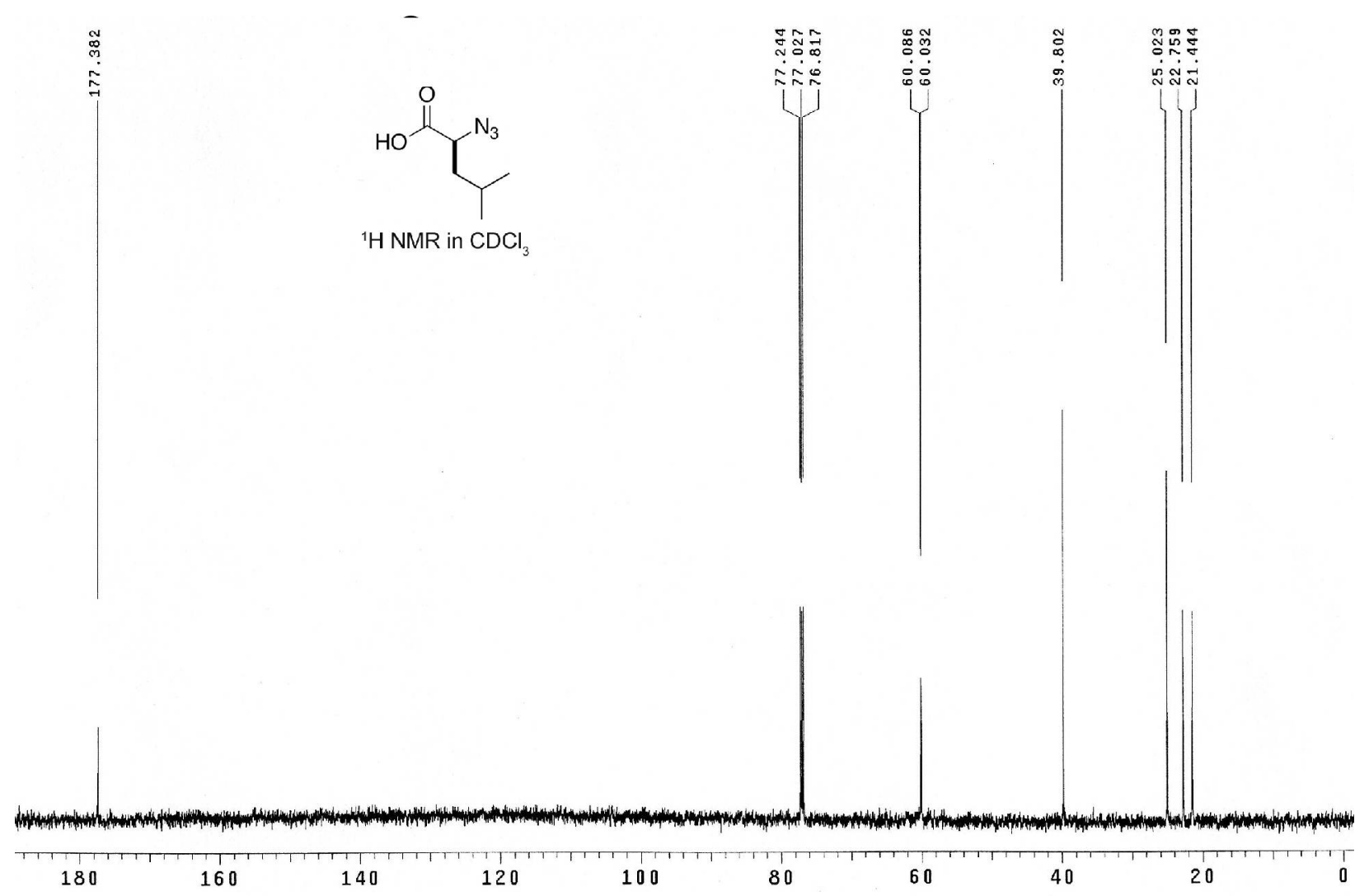

Figure S1. ${ }^{1} \mathrm{H}$ NMR (top) and ${ }^{13} \mathrm{C}$ NMR (bottom) spectra for L-lseucine azido acid. 

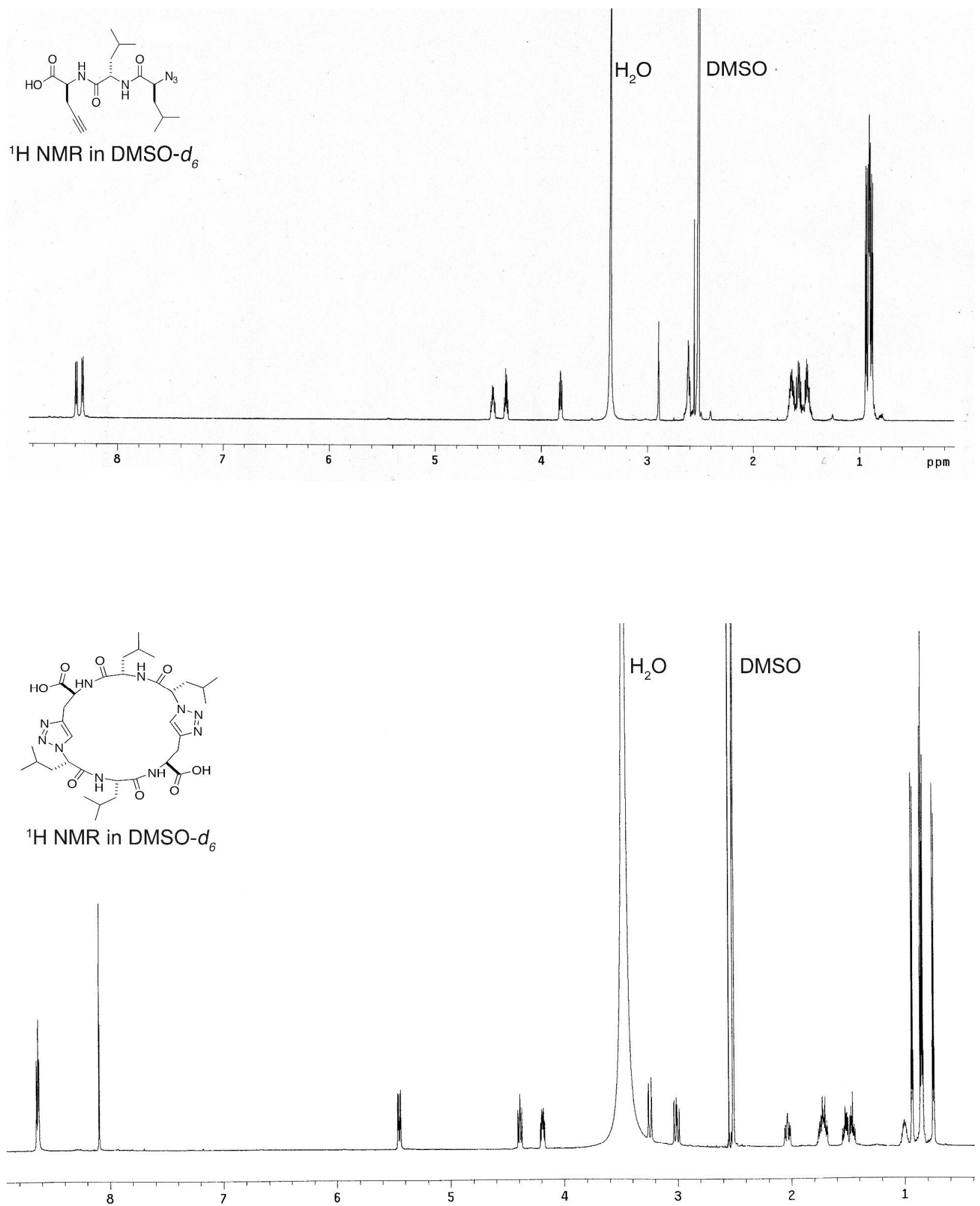

Figure S2. ${ }^{1} \mathrm{H}$ NMR spectra for linear tripeptide $\mathbf{1}$ (top), and tripeptide cyclodimer $\mathbf{1 0}$ (bottom). 


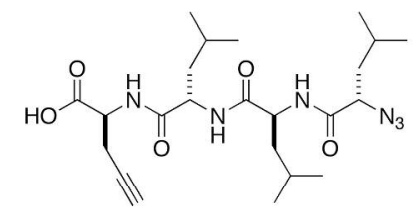

${ }^{1} \mathrm{H}$ NMR in DMSO- $d_{6}$
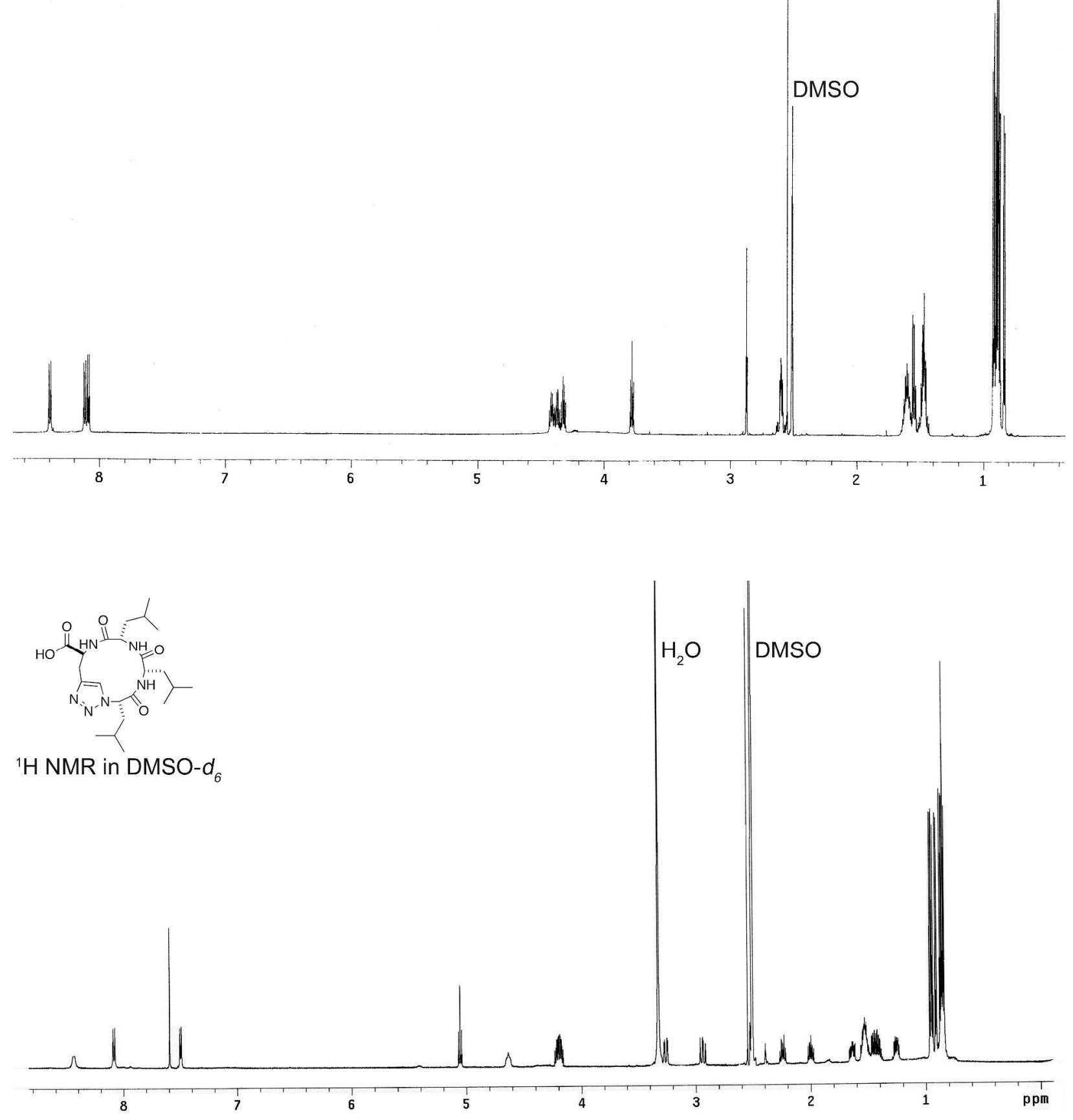

Figure S3. ${ }^{1}$ H NMR spectra for linear tetrapeptide 2 (top), and monomer 6 (bottom). 


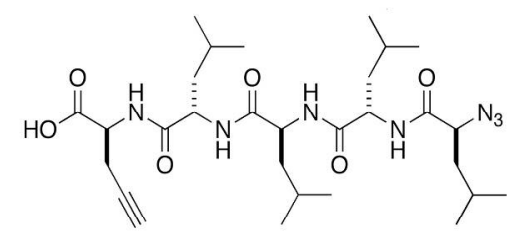

${ }^{1} \mathrm{H}$ NMR in DMSO- $d_{6}$

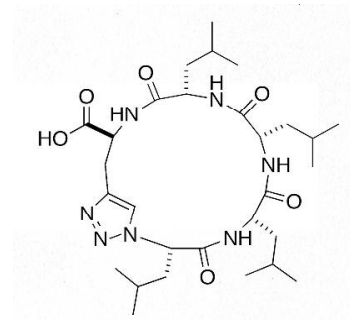

${ }^{1} \mathrm{H}$ NMR in DMSO- $d_{6}$
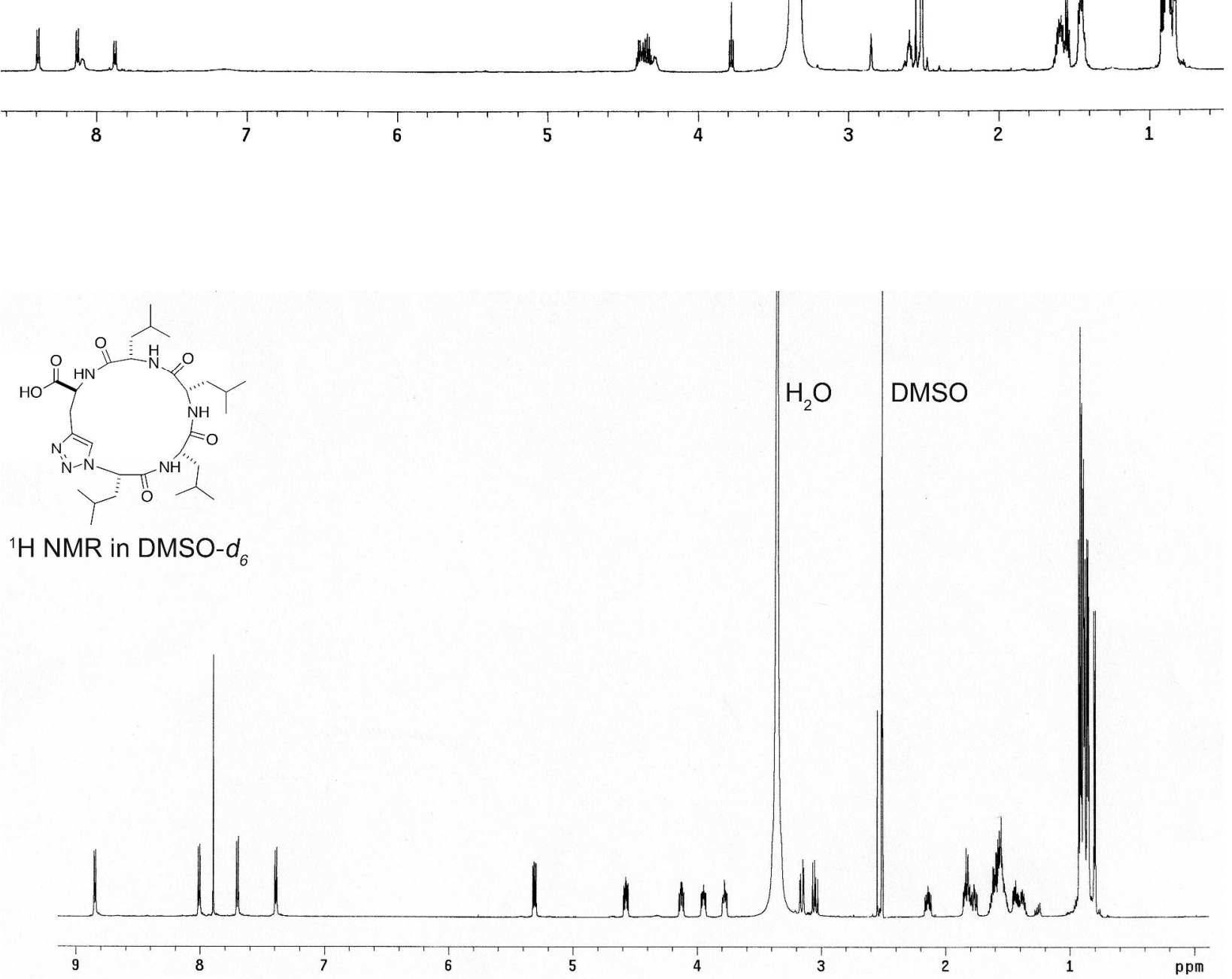

Figure S4. ${ }^{1}$ H NMR spectra for linear pentapeptide 3 (top), and monomer 7 (bottom). 

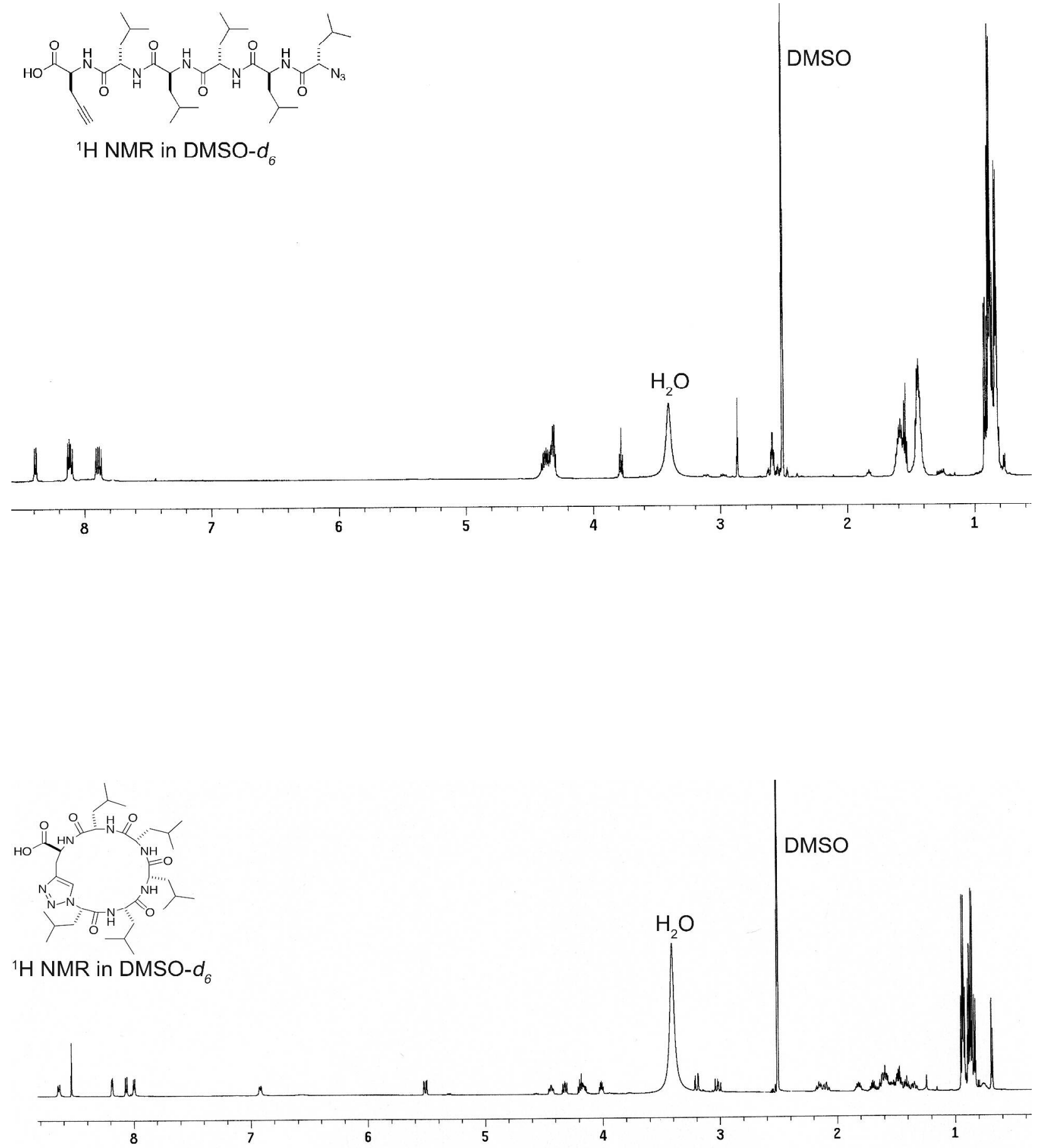

Figure S5. ${ }^{1}$ H NMR spectra for linear hexapeptide 4 (top), and monomer 8 (bottom). 

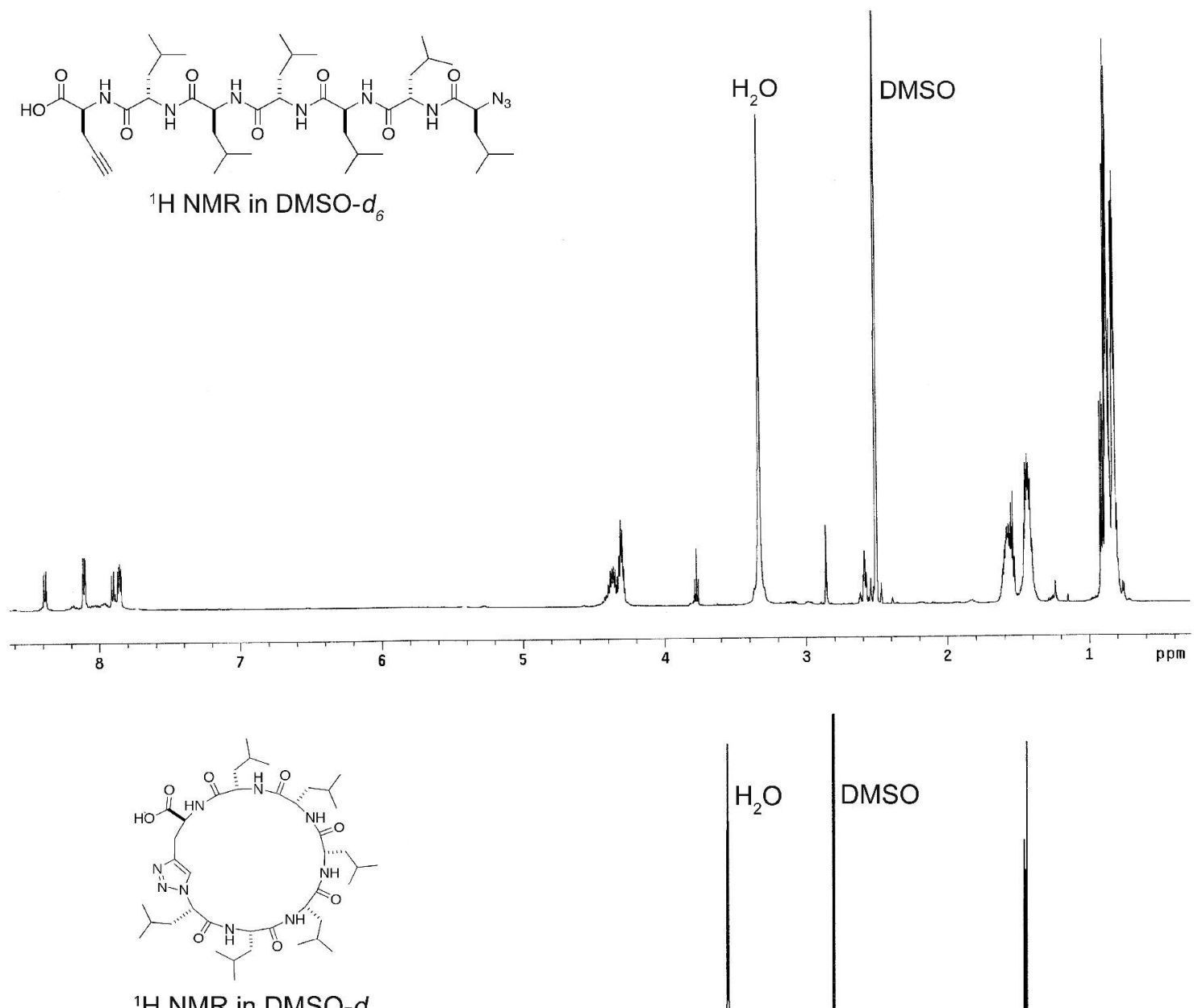

${ }^{1} \mathrm{H}$ NMR in DMSO- $d_{6}$

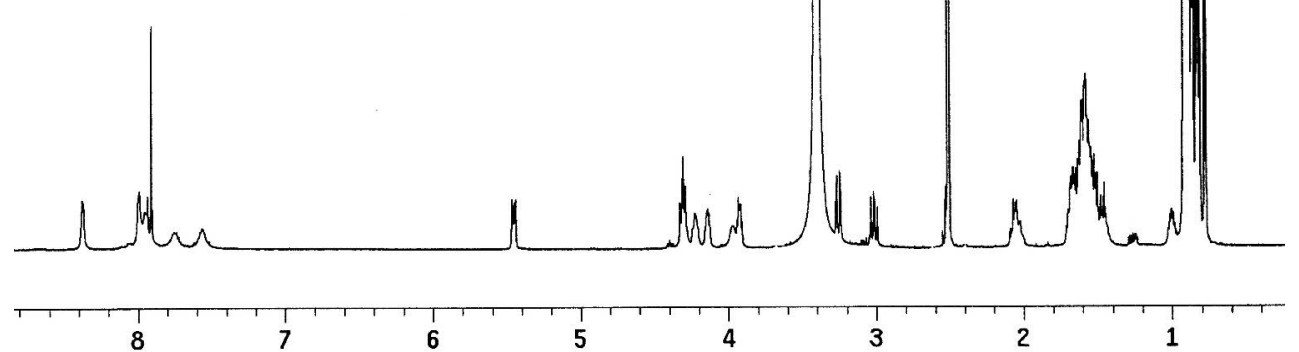

Figure S6. ${ }^{1}$ H NMR spectra for linear heptapeptide 5 (top) and monomer 9 (bottom). 

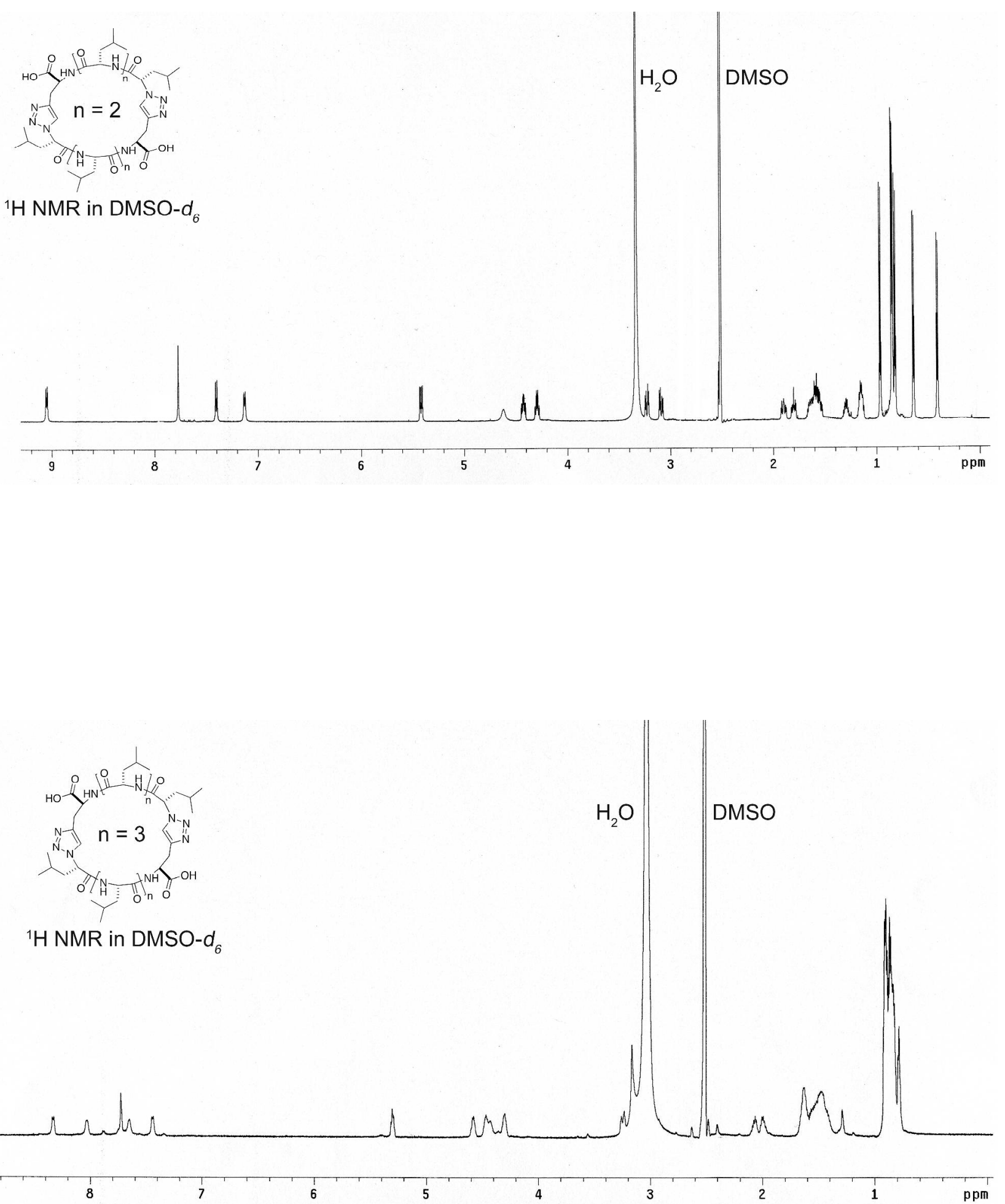

Figure S7. ${ }^{1} \mathrm{H}$ NMR spectra for tetrapeptide cyclodimer 11 (top) and pentapeptide cyclodimer 12 (bottom). 

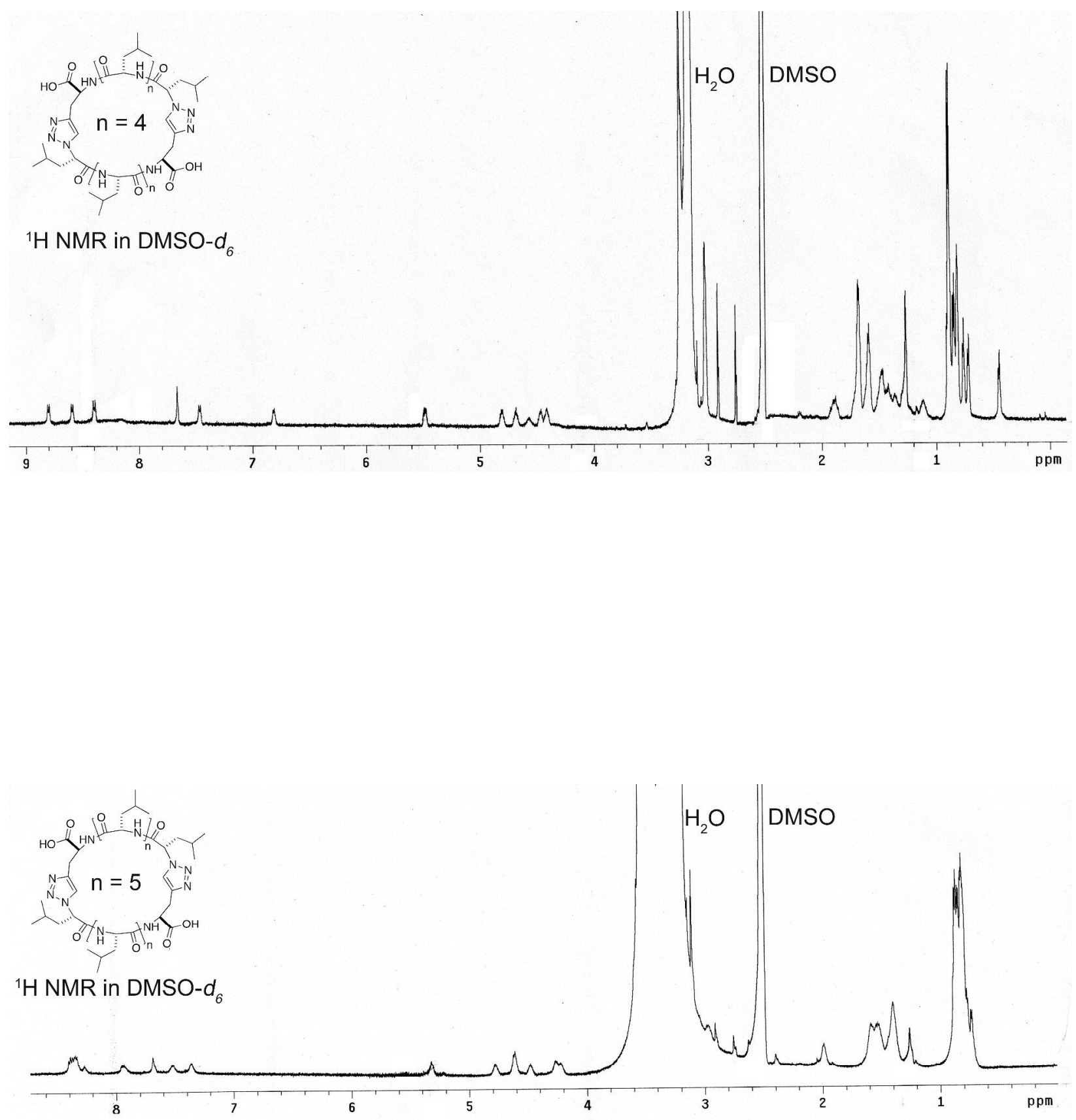

Figure S8. ${ }^{1} \mathrm{H}$ NMR spectra for hexapeptide cyclodimer 13 (top) and heptapeptide cyclodimer 14 (bottom). 


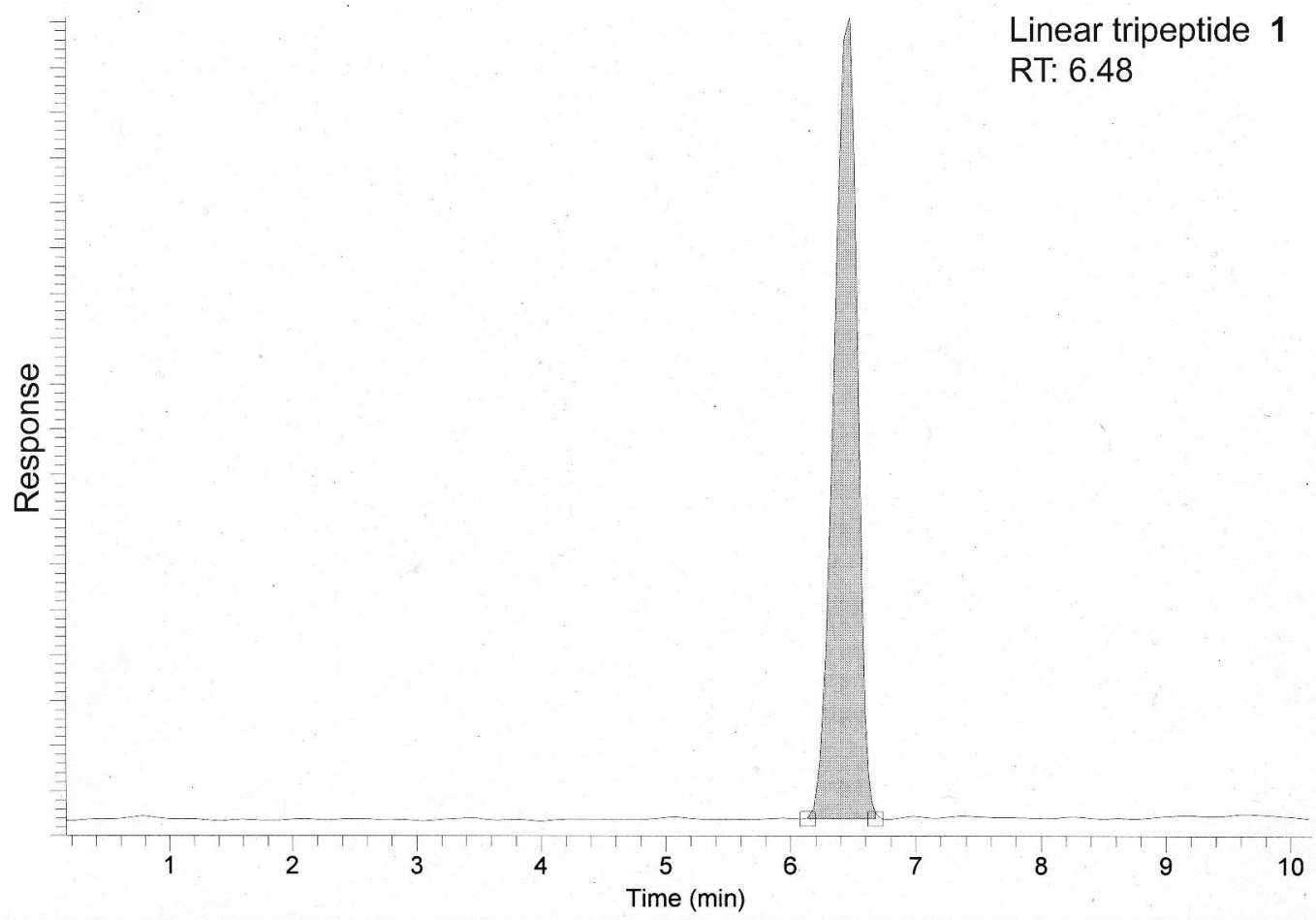

3N3-30to100 \#134 RT: 6.48 AV: 1 NL: 1.99E6

$\mathrm{T}:$ + c ESI Full ms [ 200.00-2000.00]

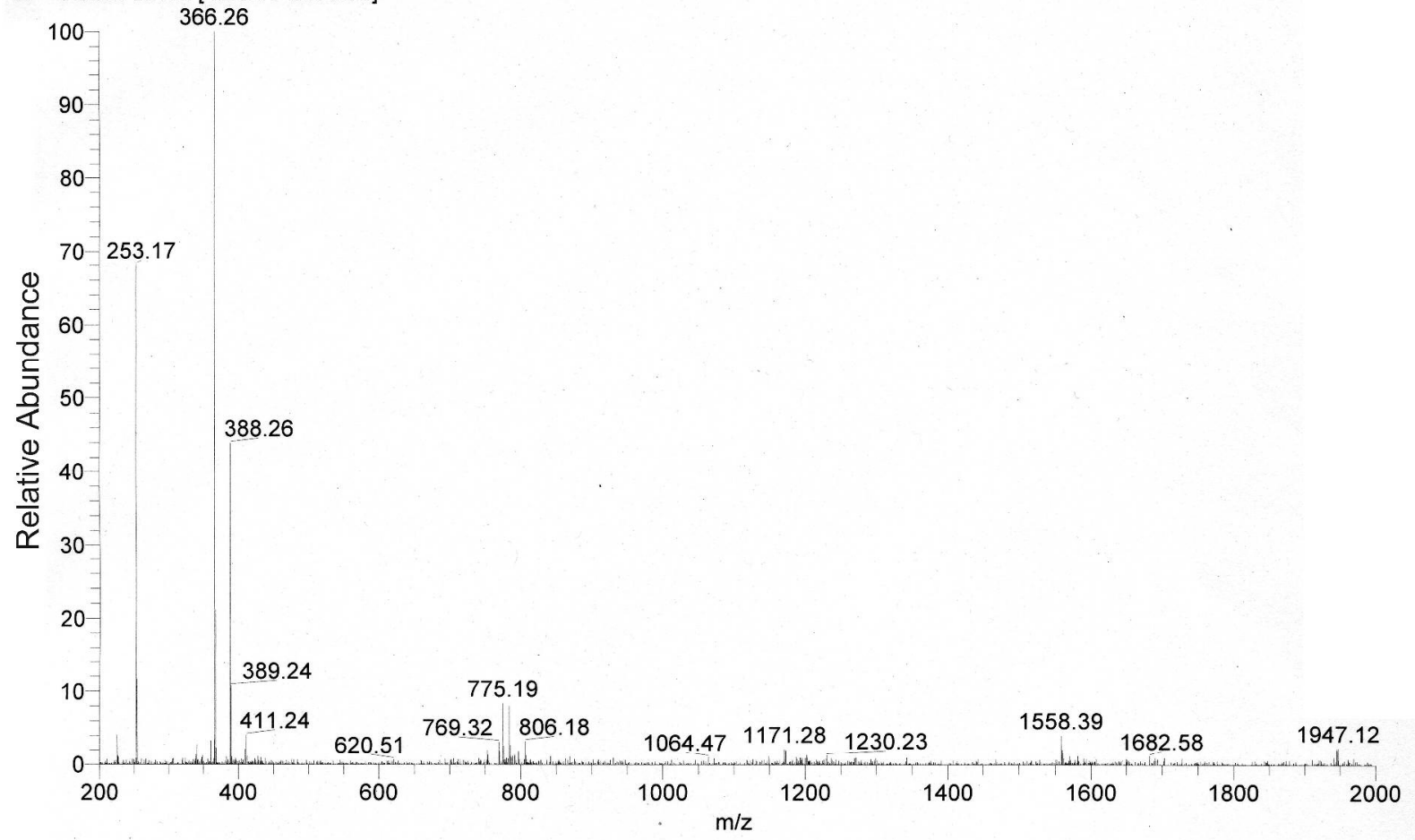

Figure S9. ELSD trace (top) and MS (bottom) of crude linear tripeptide 1. 


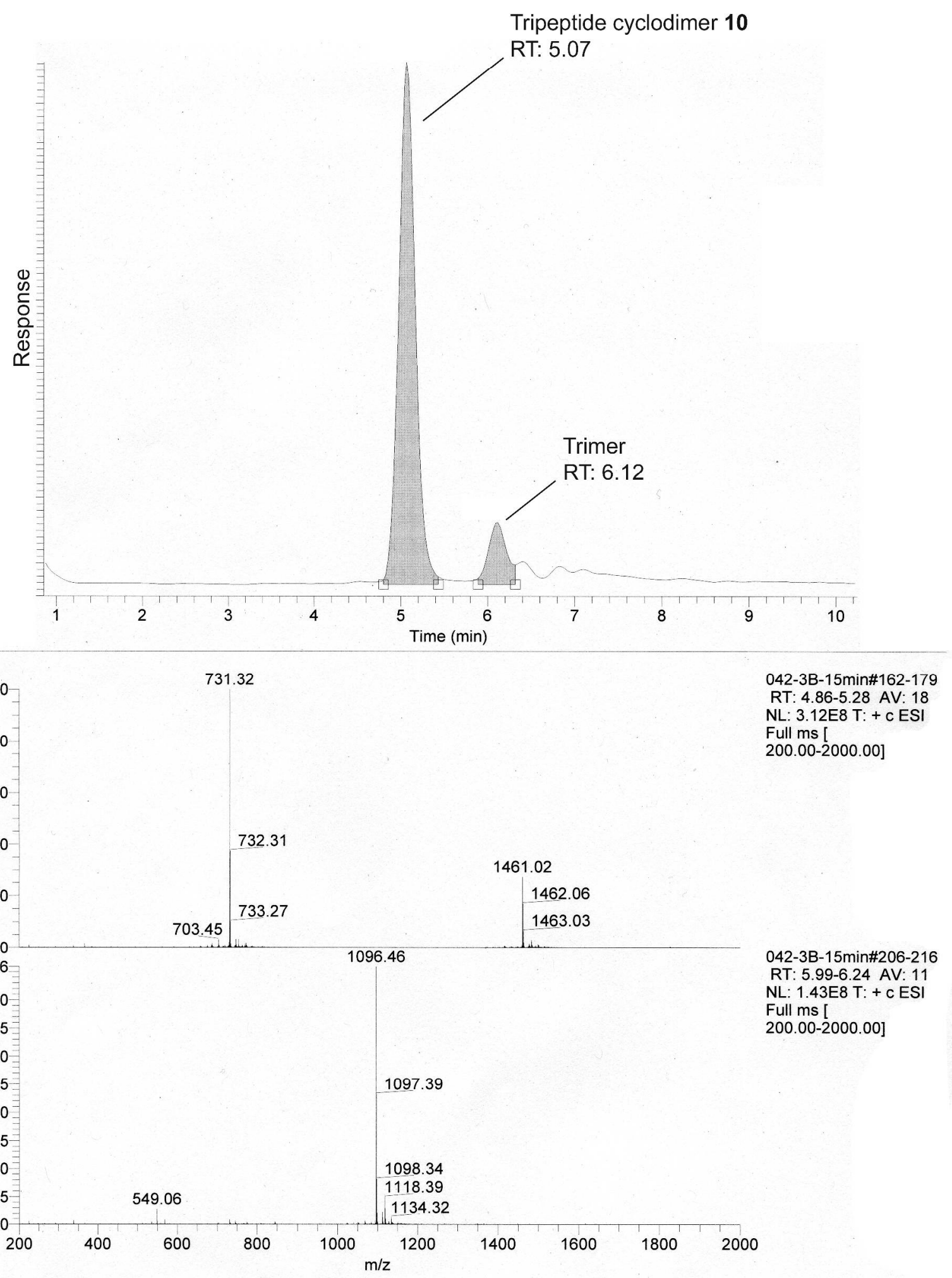

Figure S10. ELSD trace (top) and MS (bottom) of crude reaction mixture for the copper mediated cyclization of tripeptide $\mathbf{1}$, showing cyclodimer $\mathbf{1 0}$ and trimer products. 


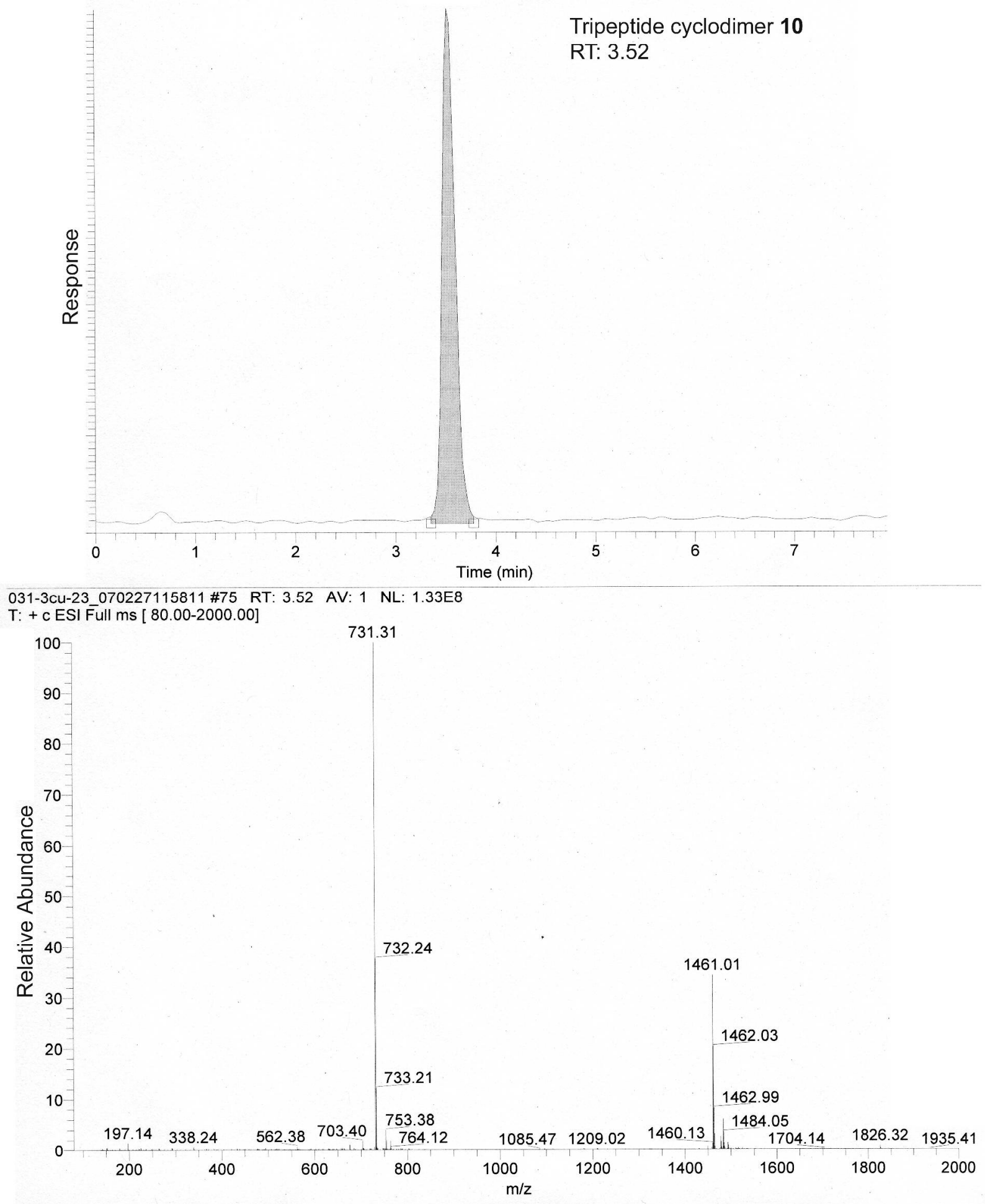

Figure S11. ELSD trace (top) and MS (bottom) of purified tripeptide cyclodimer 10. 

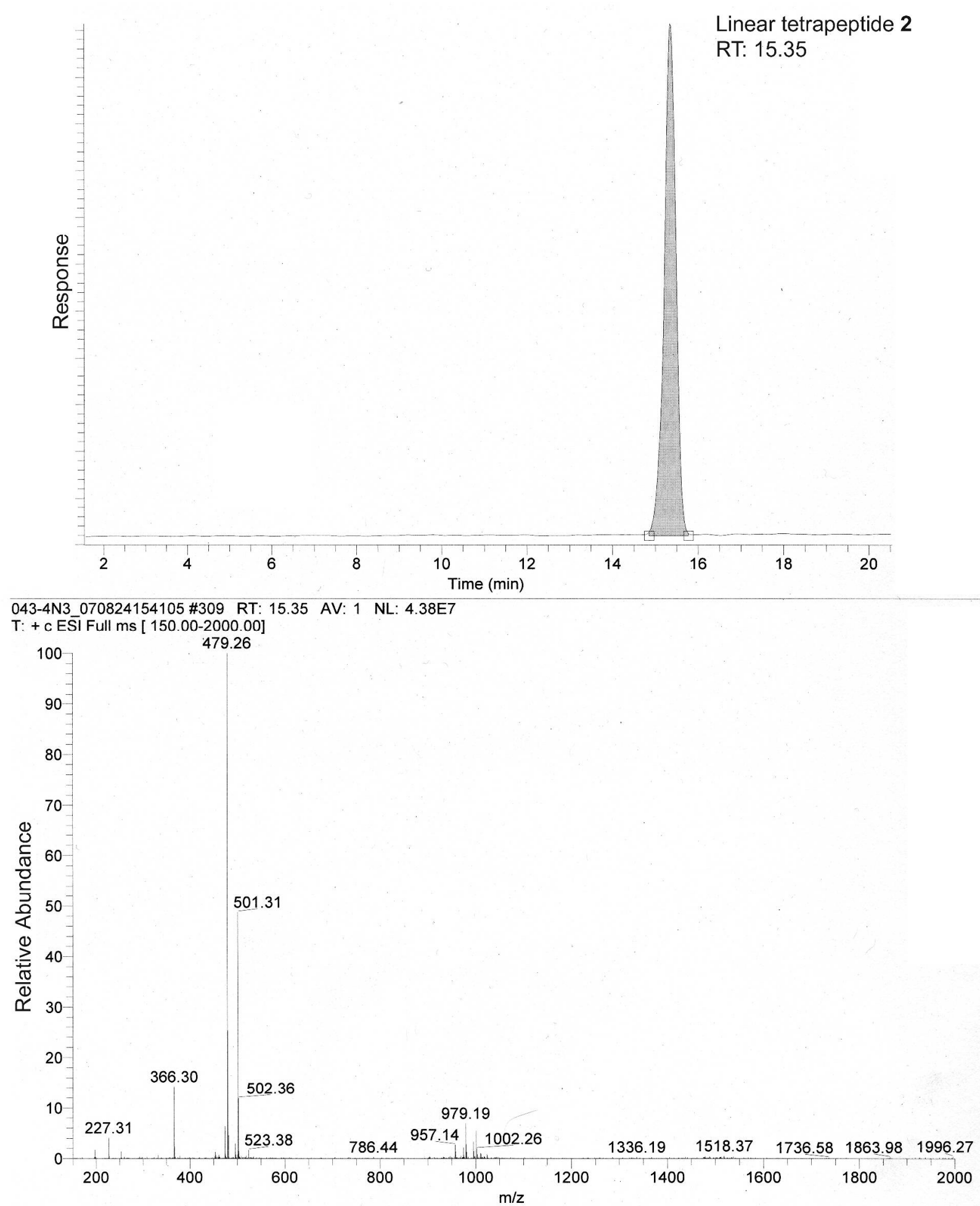

Figure S12. ELSD trace (top) and MS (bottom) of crude linear tetrapeptide 2. 

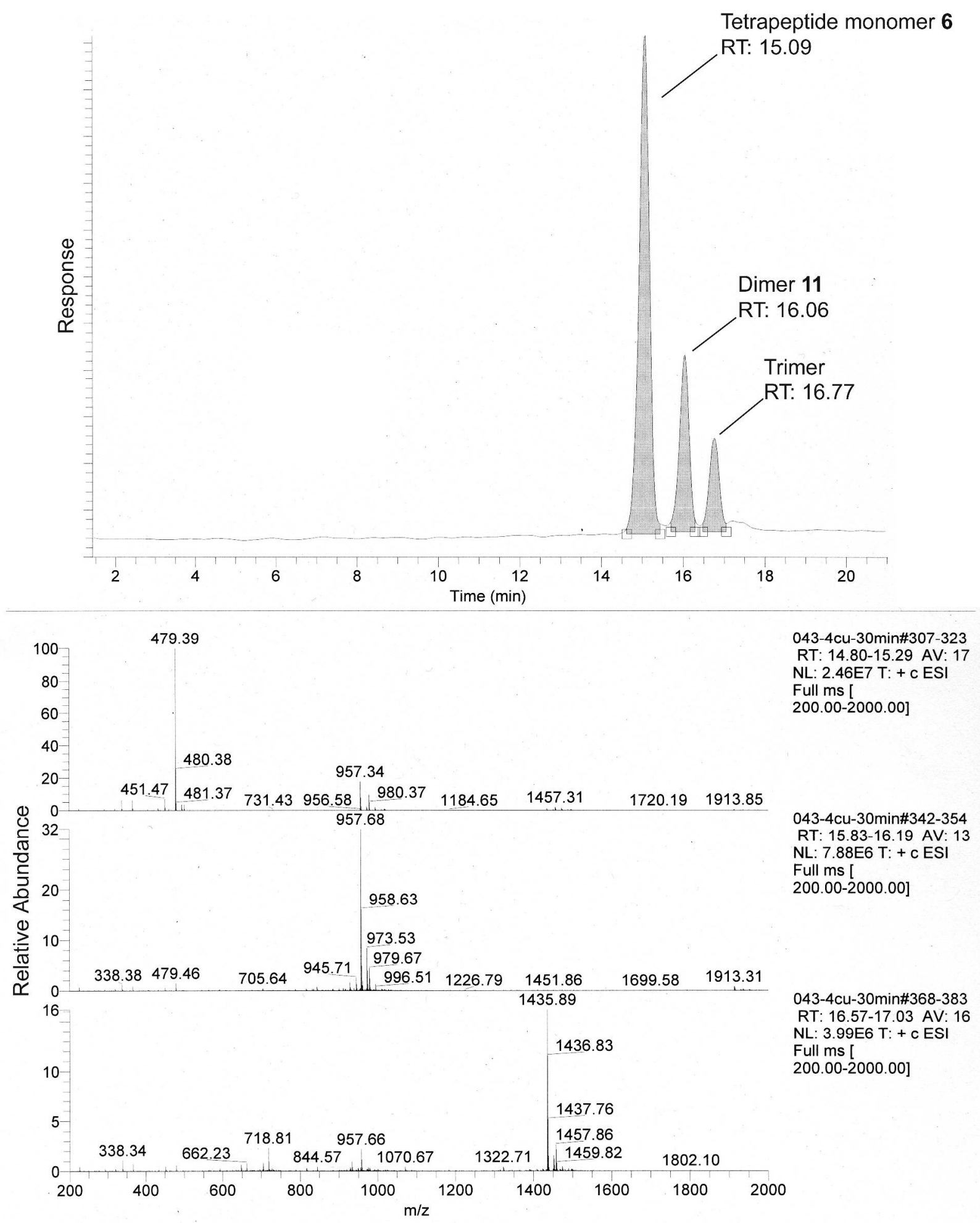

Figure S13. ELSD trace and MS (bottom) of crude reaction mixture for the copper mediated cyclization of tetrapeptide $\mathbf{2}$, showing monomer $\mathbf{6}$, dimer $\mathbf{1 1}$, and trimer products. 


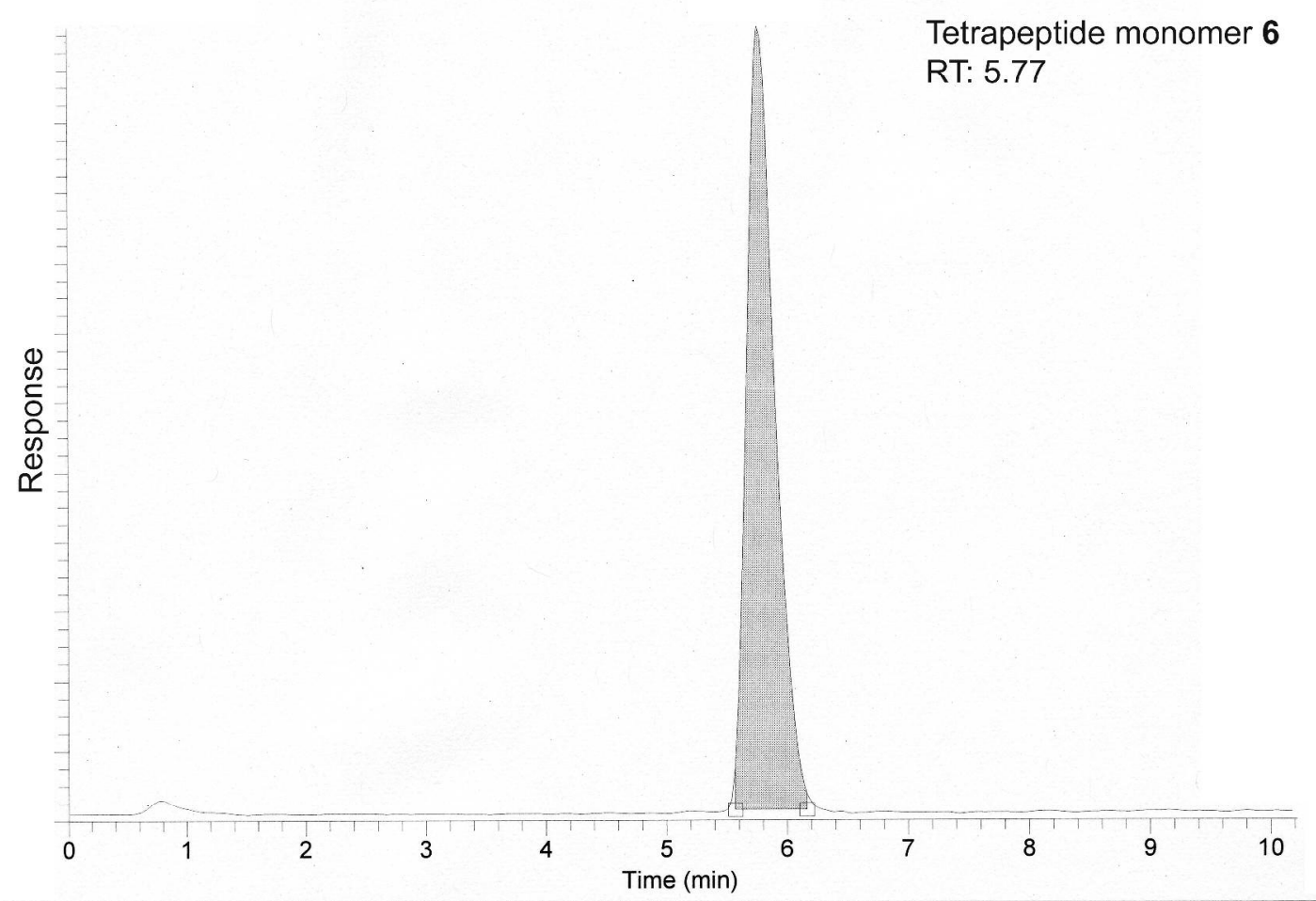

4-mono-15min \#124 RT: 5.77 AV: 1 NL: 1.27E8

$\mathrm{T}:+\mathrm{c}$ ESI Full ms [ 180.00-2000.00]

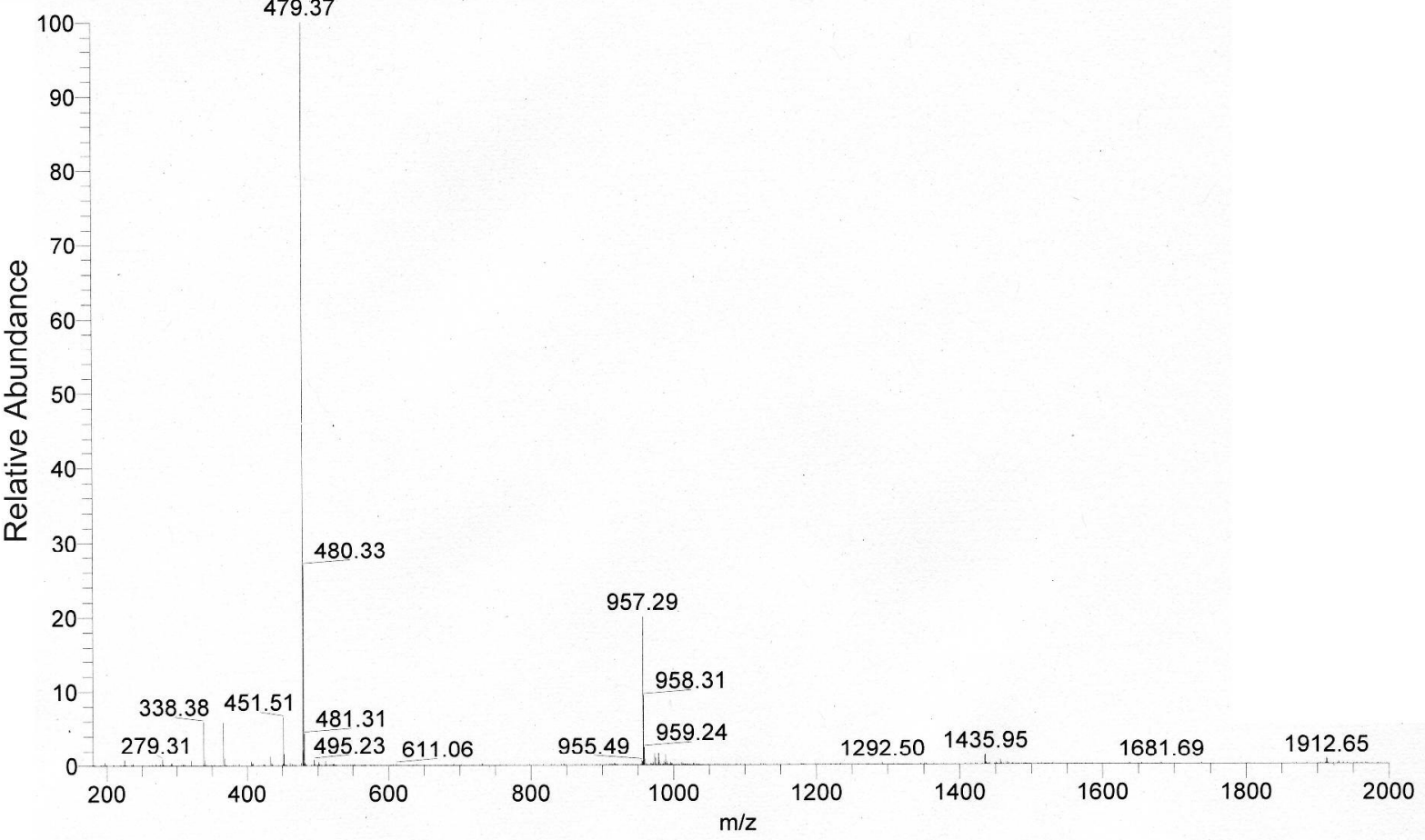

Figure S14. ELSD trace (top) and MS (bottom) of purified tetrapeptide monomer 6. 


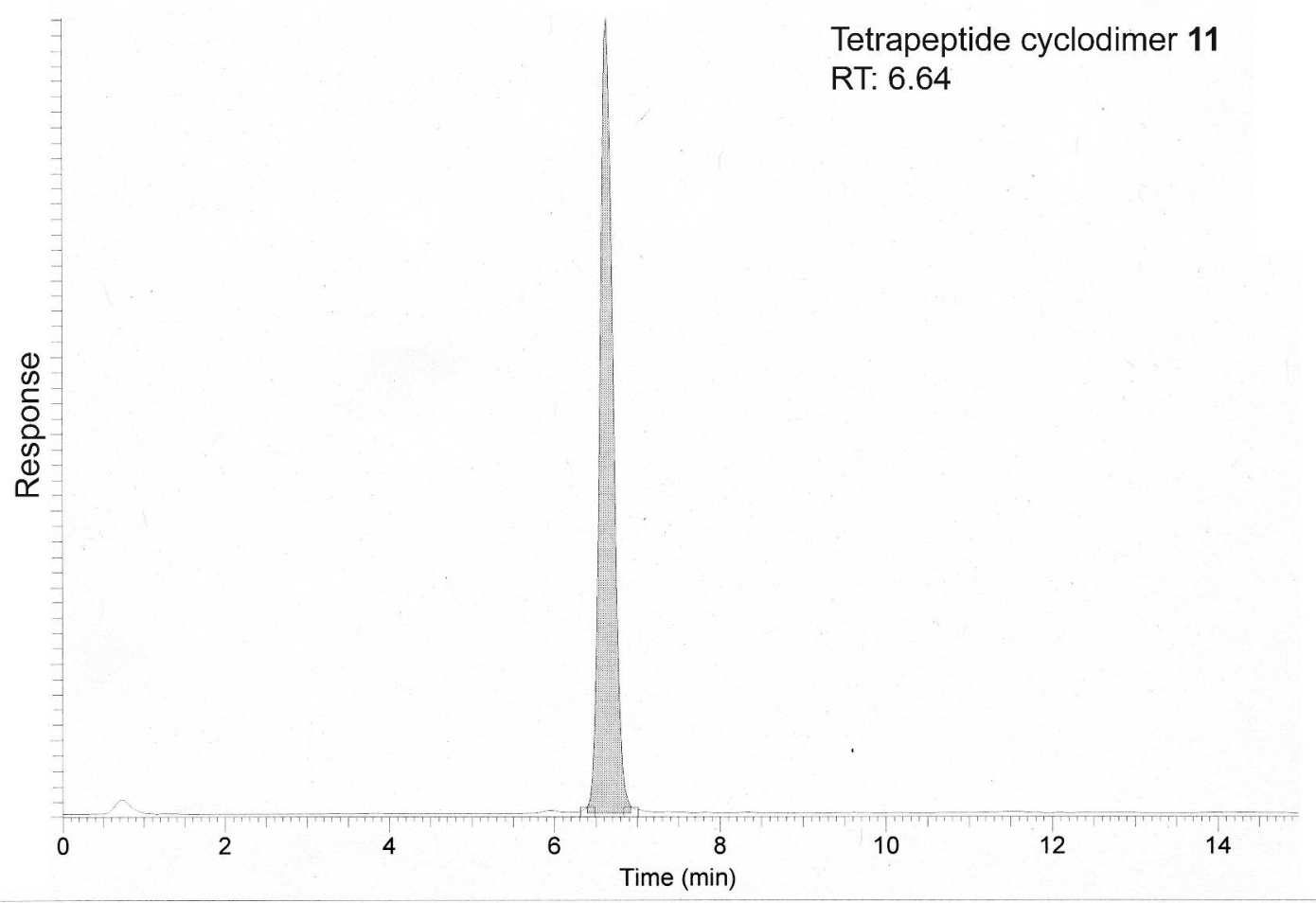

4-dimer 070904193343 \#143-156 RT: 6.49-6.80 AV: 14 NL: 1.66E8 T: + c ESI Full ms [ 180.00-2000.00]

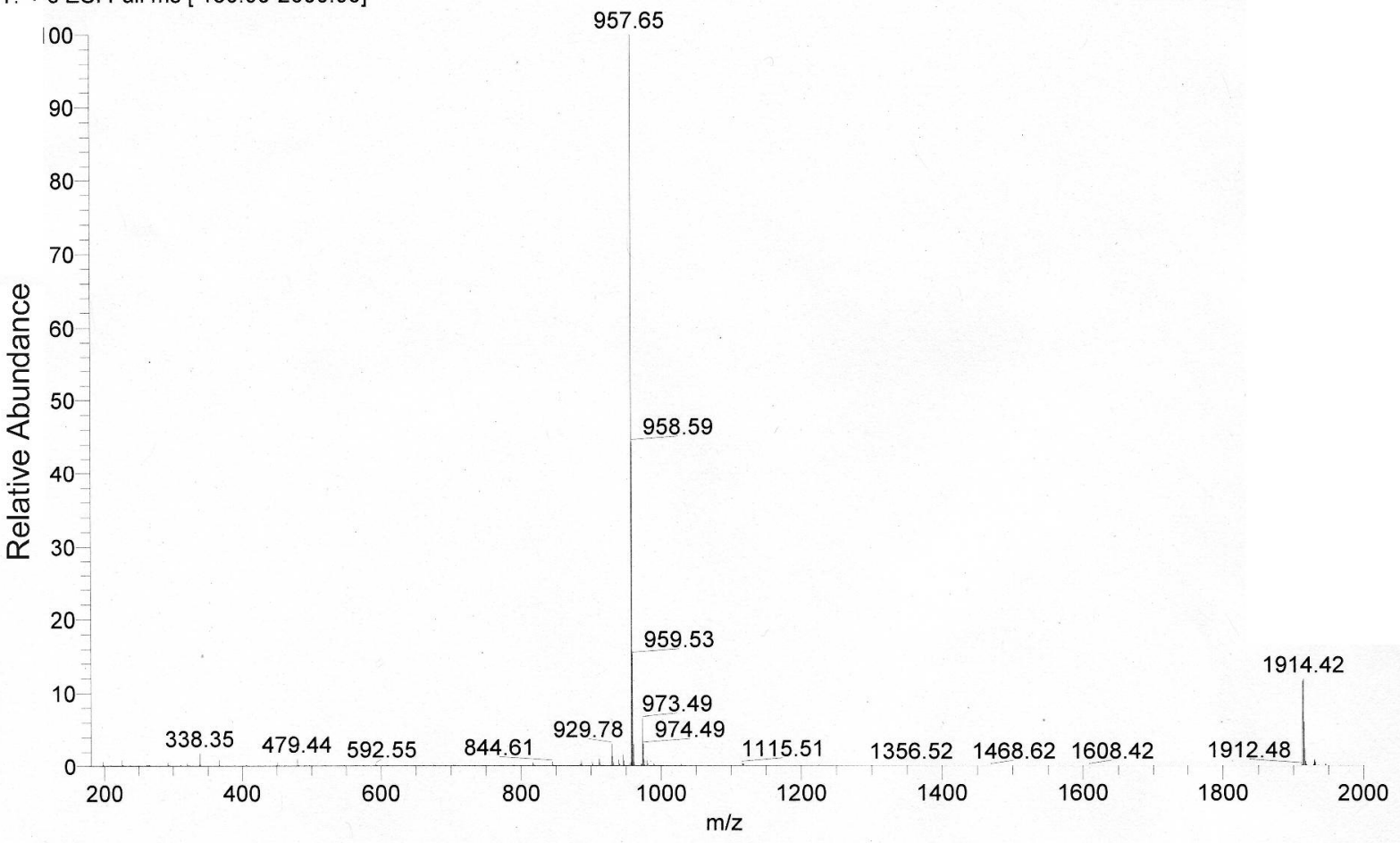

Figure S15. ELSD trace (top) and MS (bottom) of purified tetrapeptide cyclodimer 11. 

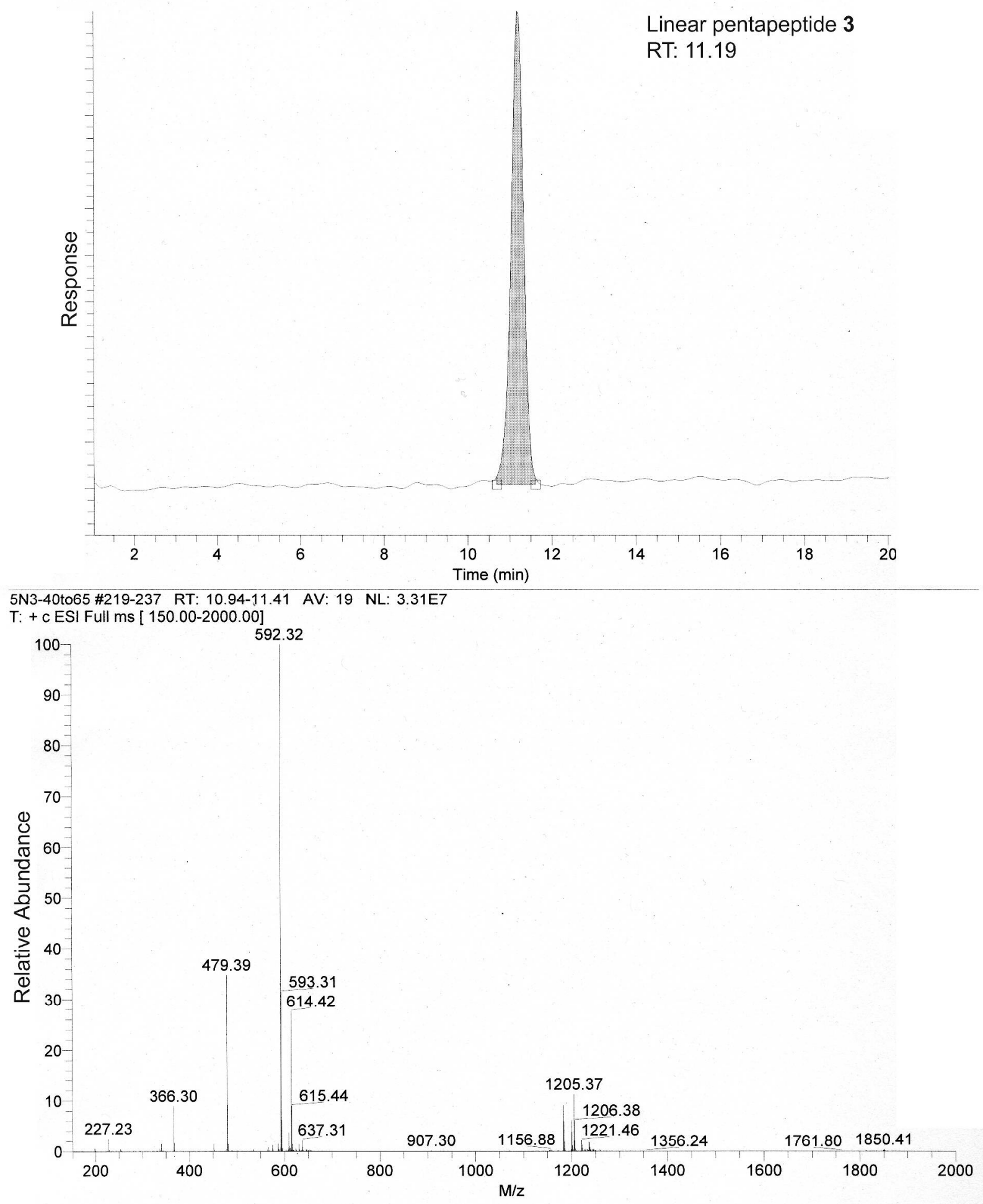

Figure S16. ELSD trace (top) and MS (bottom) of crude linear pentapeptide 3. 


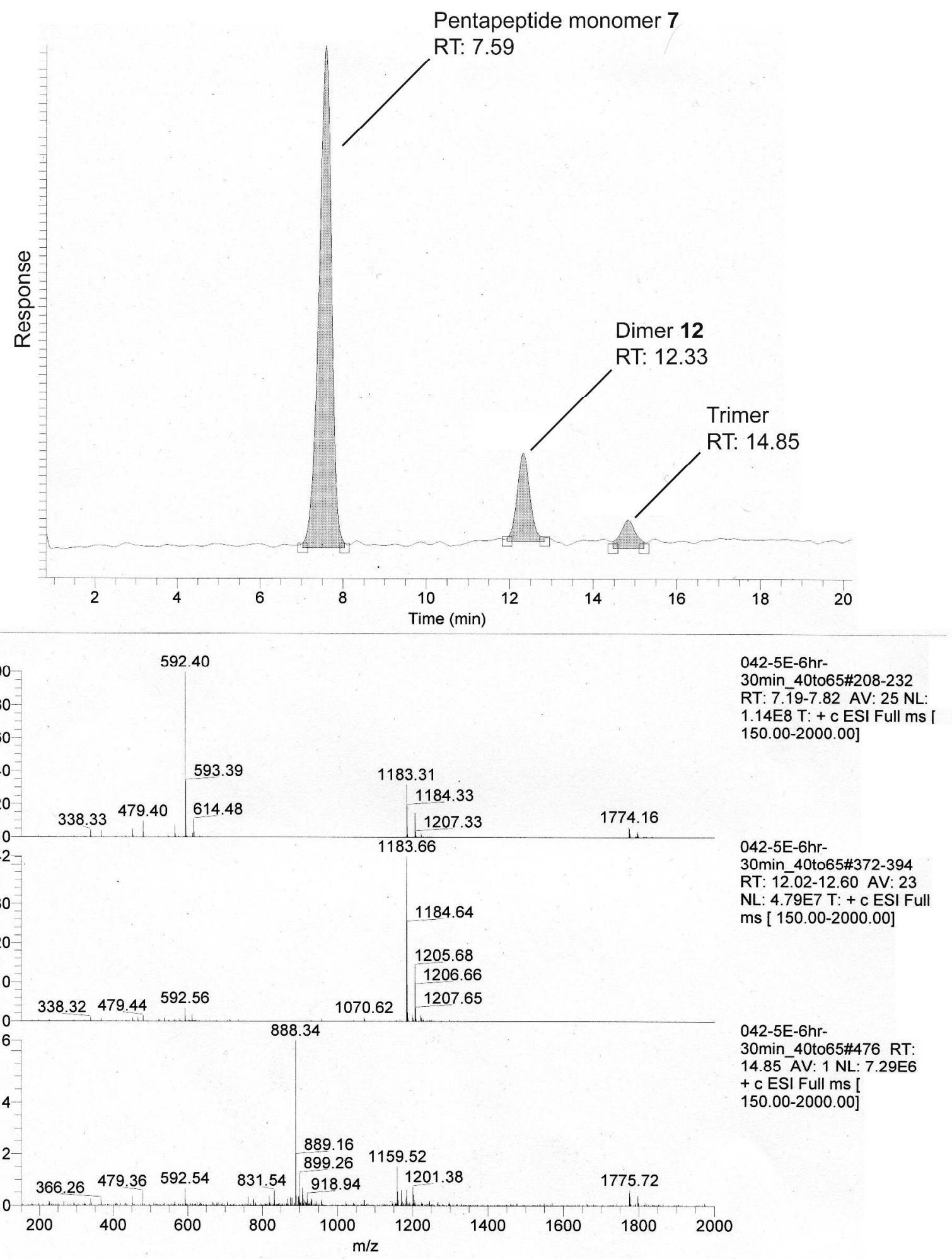

Figure S17. ELSD trace (top) and MS (bottom) of crude reaction mixture for the copper mediated cyclization of pentapeptide $\mathbf{3}$, showing monomer $\mathbf{7}$, dimer $\mathbf{1 2}$, and trimer products. 


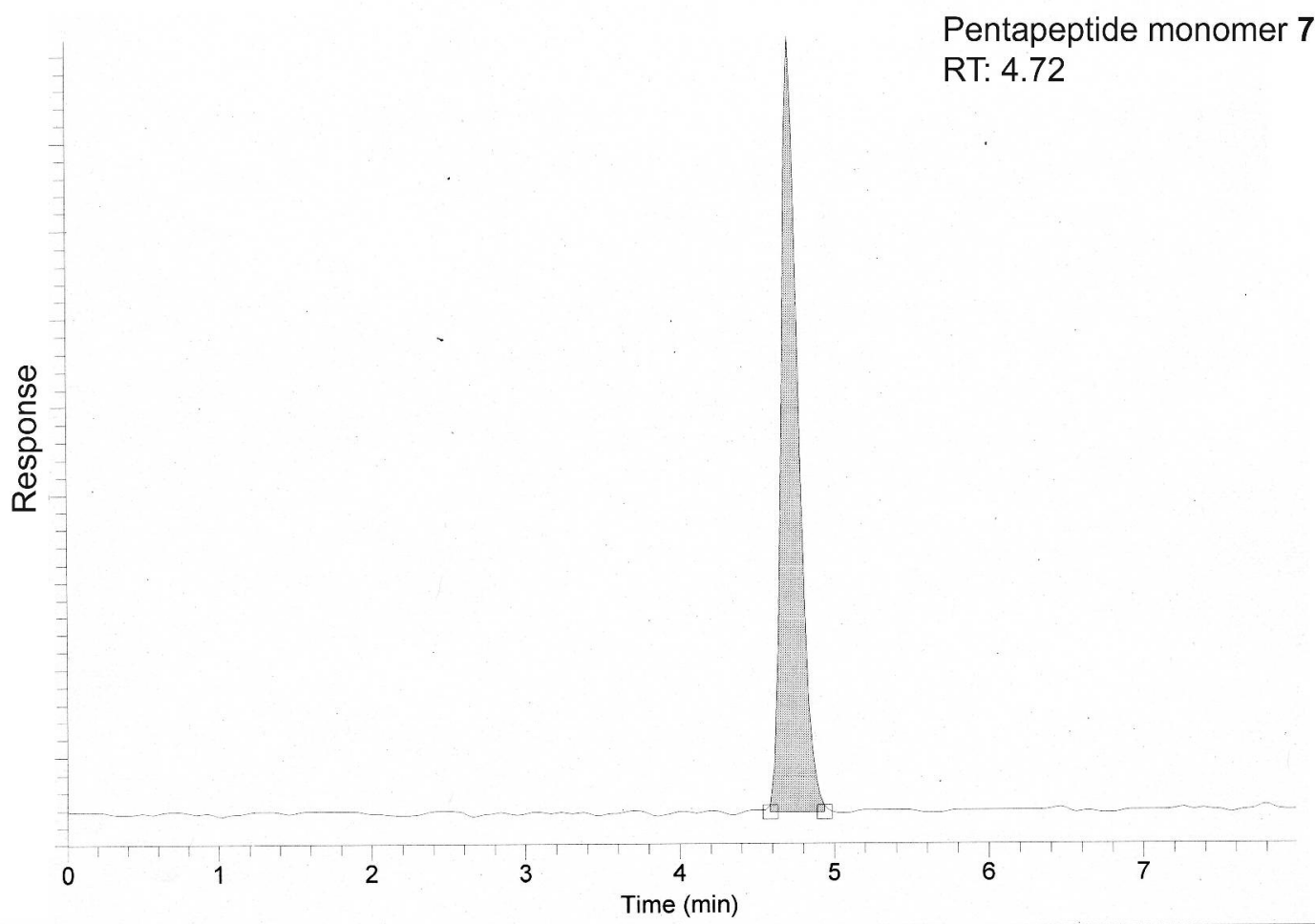

5cu-21\#132-143 RT: 4.61-4.88 AV: 12 NL: 3.00E8

T: + c ESI Full ms [ 80.00-2000.00]

100

592.30

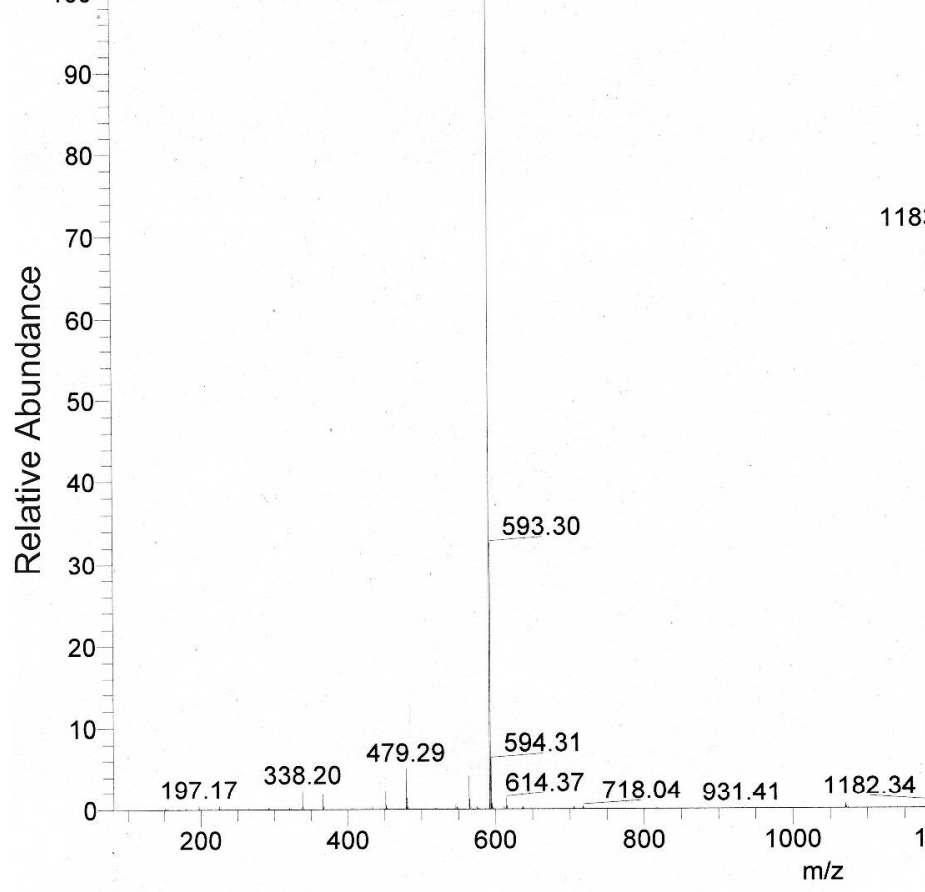

183.20

1184.22

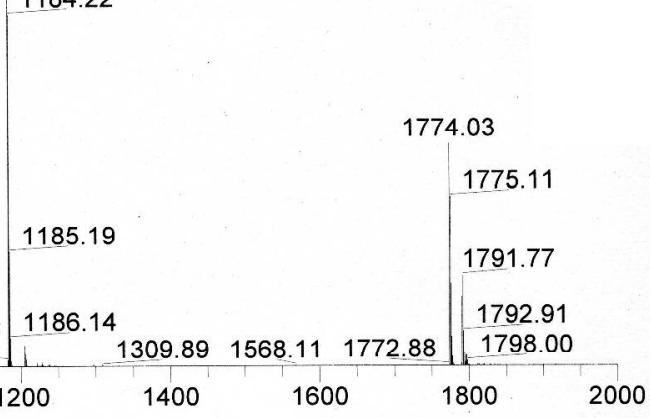

Figure S18. ELSD trace (top) and MS (bottom) of purified pentapeptide monomer 7. 


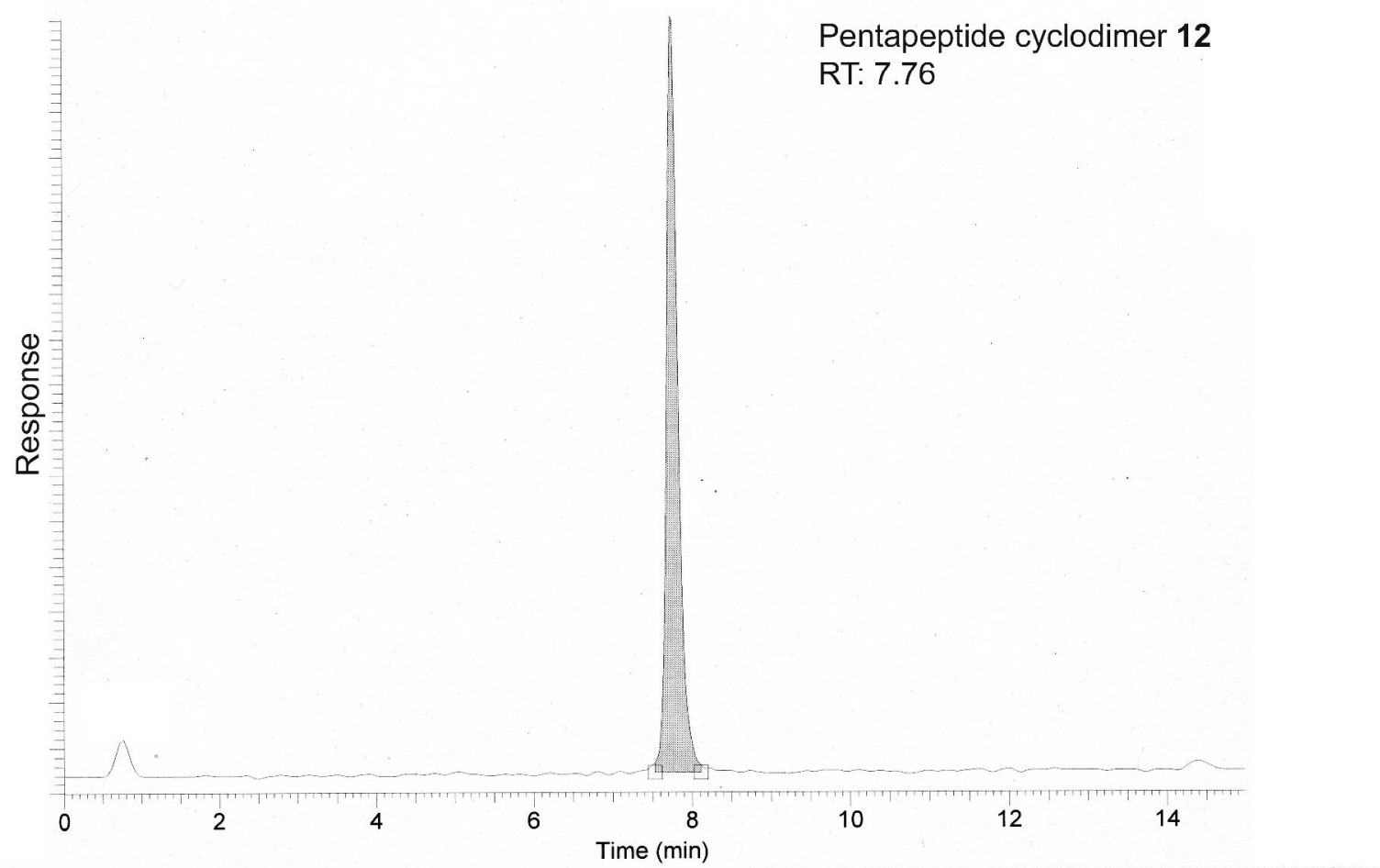

5-dimer-4HRMS \#164-173 RT: 7.65-7.88 AV: 10 NL: 9.74E7

T: + c ESI Full ms [ 180.00-2000.00]

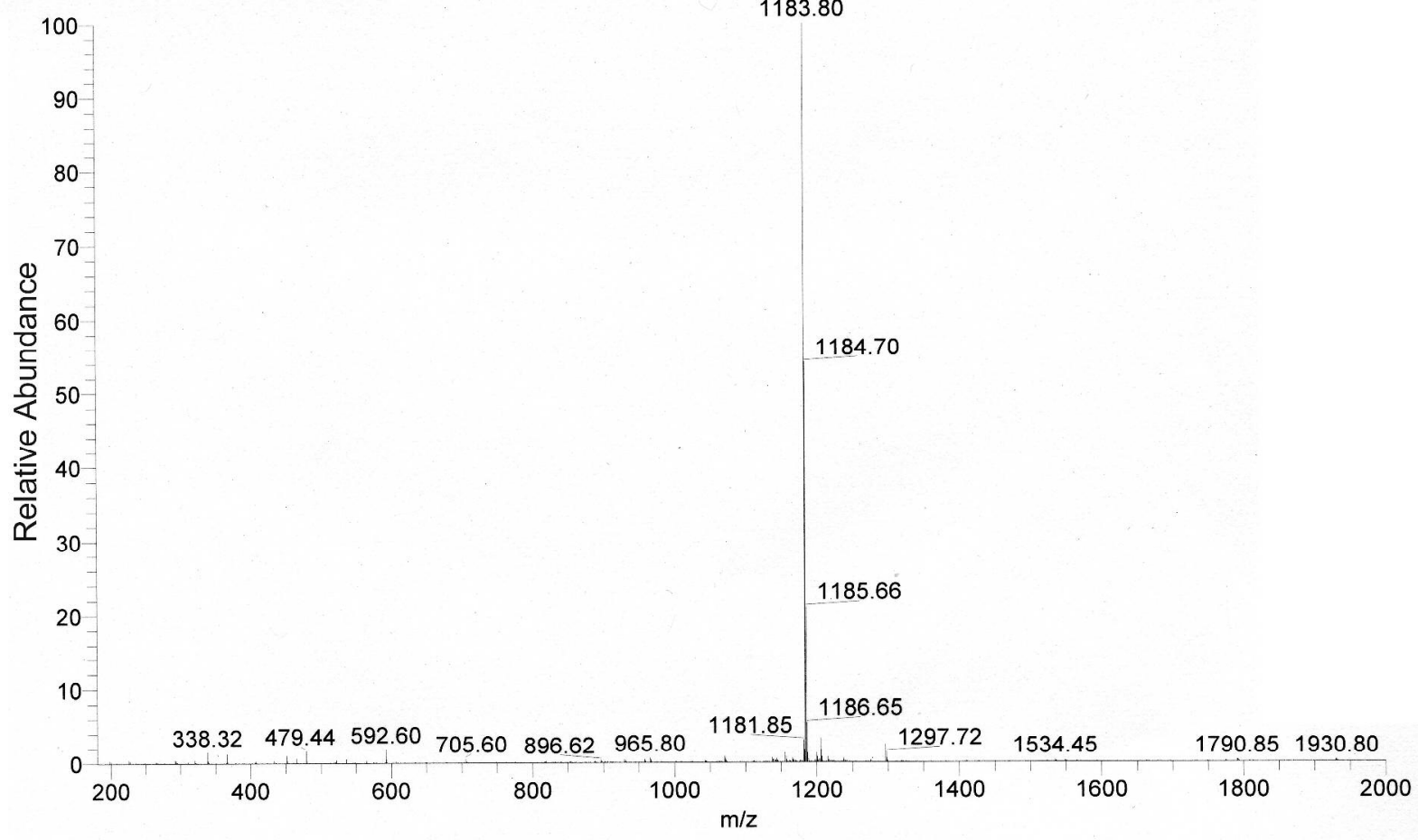

Figure S19. ELSD trace (top) and MS (bottom) of purified pentapeptide cyclodimer 12. 


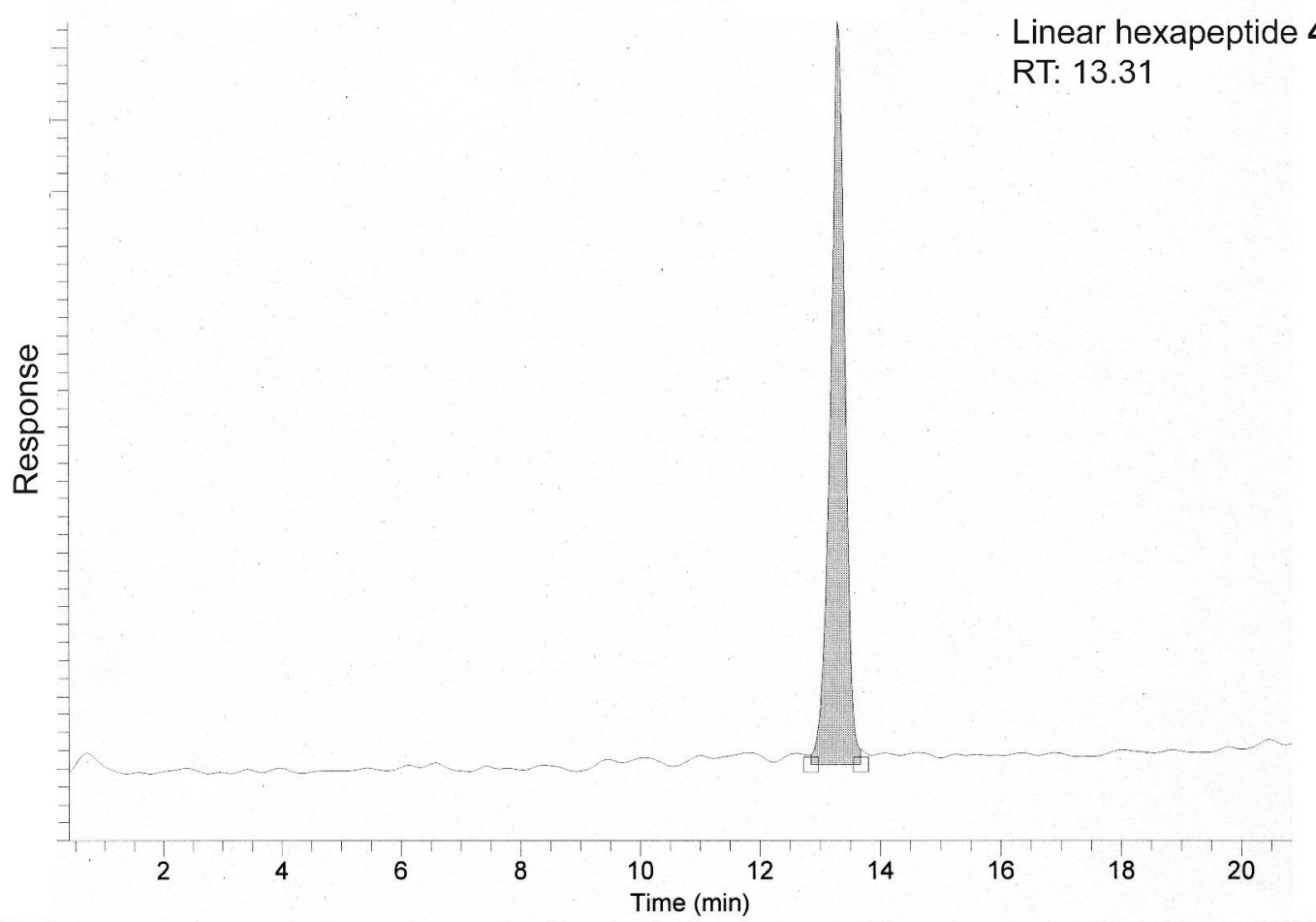

043-6N3-30to100 \#257-275 RT: 12.99-13.55 AV: 19 NL: $2.13 E 7$

T: + c ESI Full ms [ 150.00-2000.00]

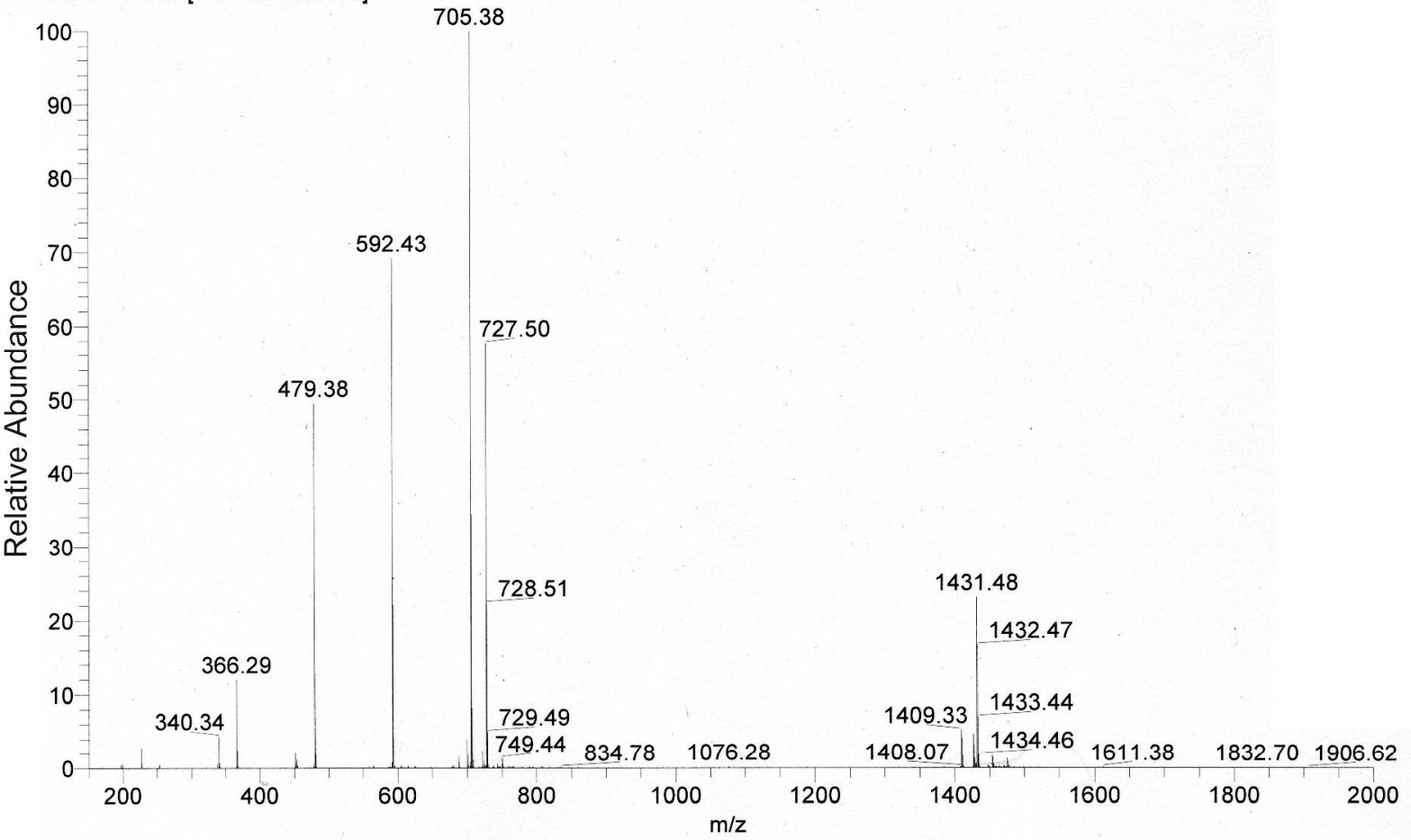

Figure S20. ELSD trace (top) and MS (bottom) of crude linear hexapeptide 4. 


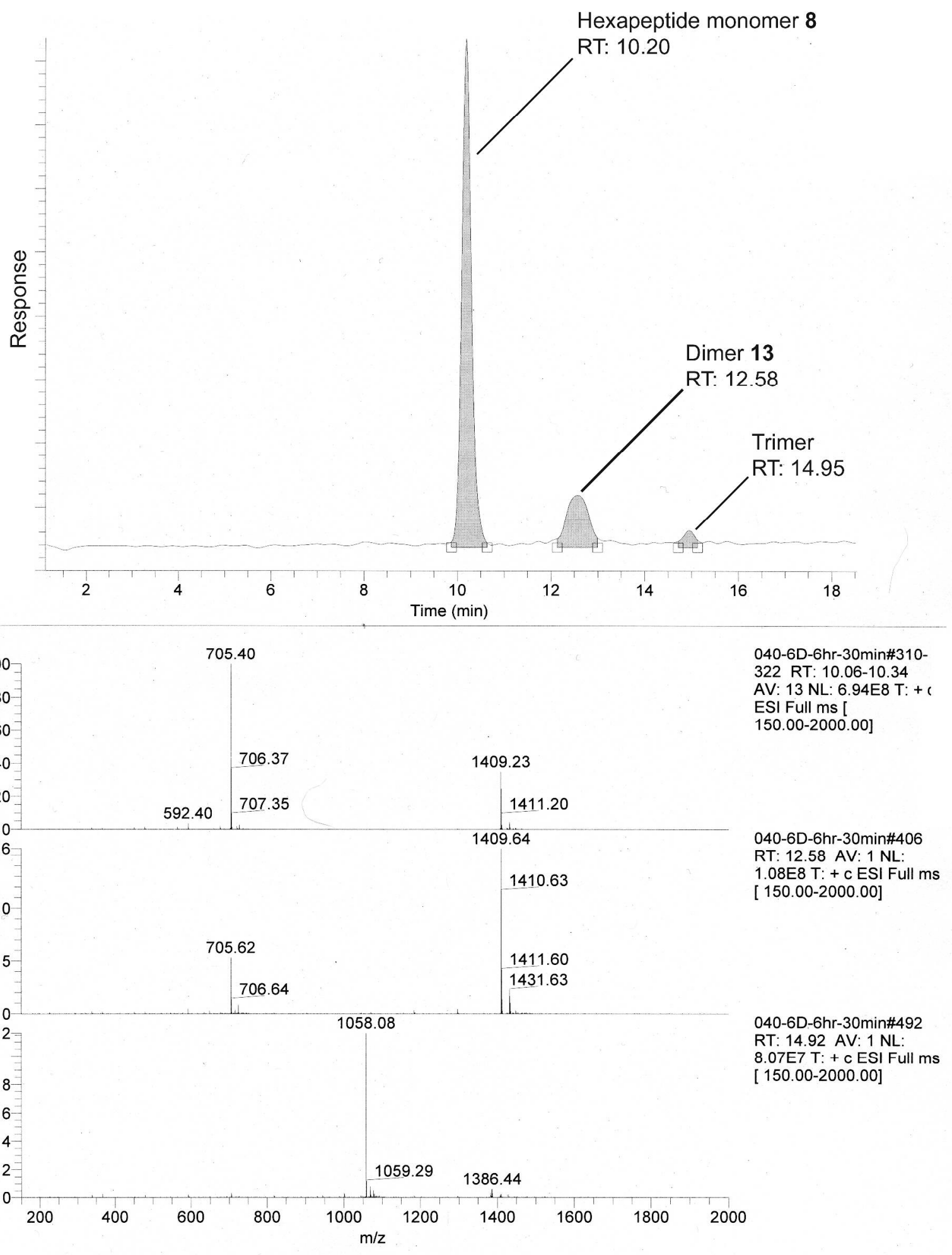

Figure S21. ELSD trace (top) and MS (bottom) of crude reaction mixture for the copper mediated cyclization of hexapeptide $\mathbf{4}$, showing monomer $\mathbf{8}$, dimer $\mathbf{1 3}$, and trimer products. 


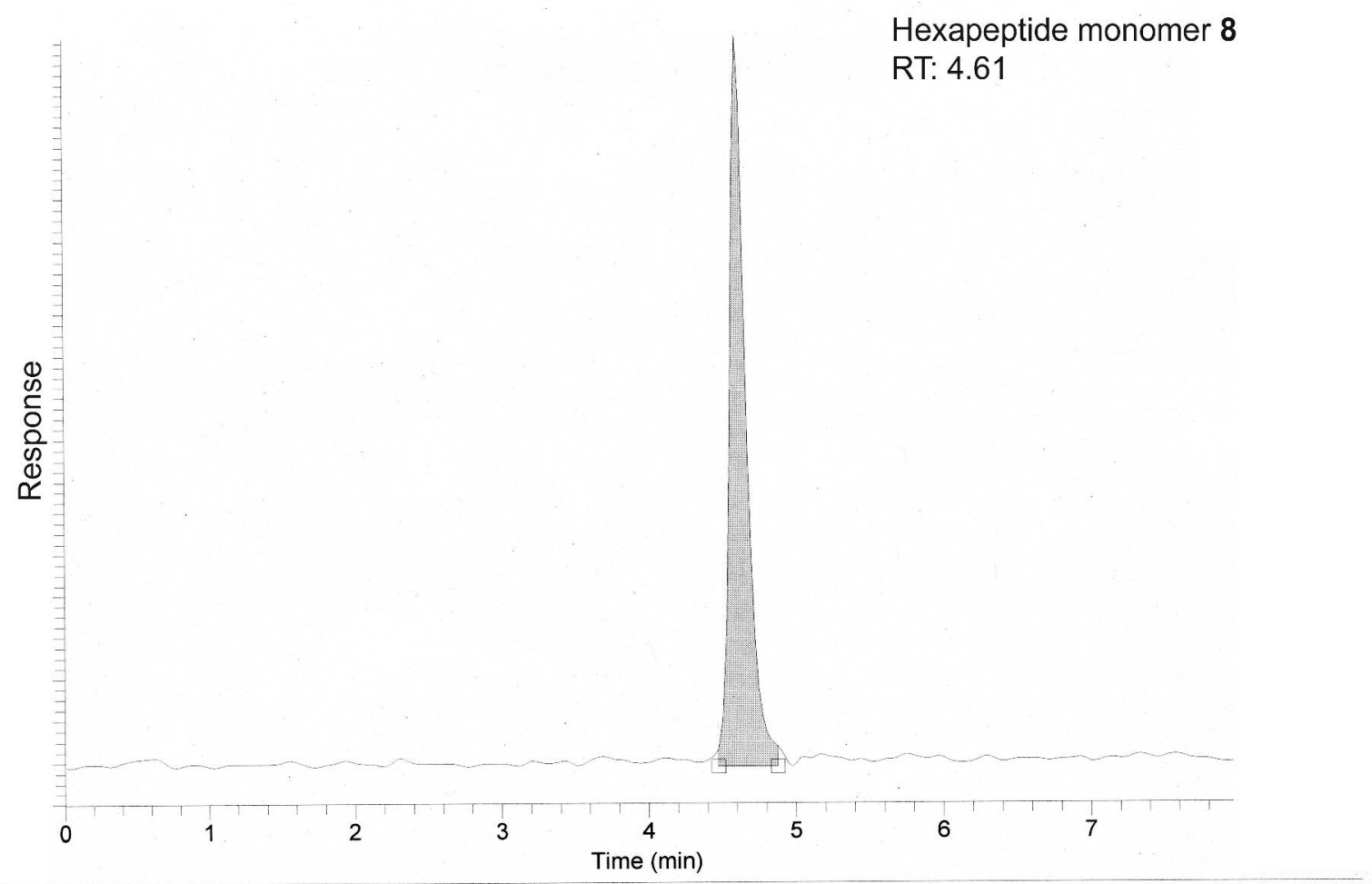

RTII021-6cu-fr26 \#132-142 RT: 4.50-4.75 AV: 11 NL: 4.21E8

$\mathrm{T}$ : + c ESI Full ms [ 80.00-2000.00]

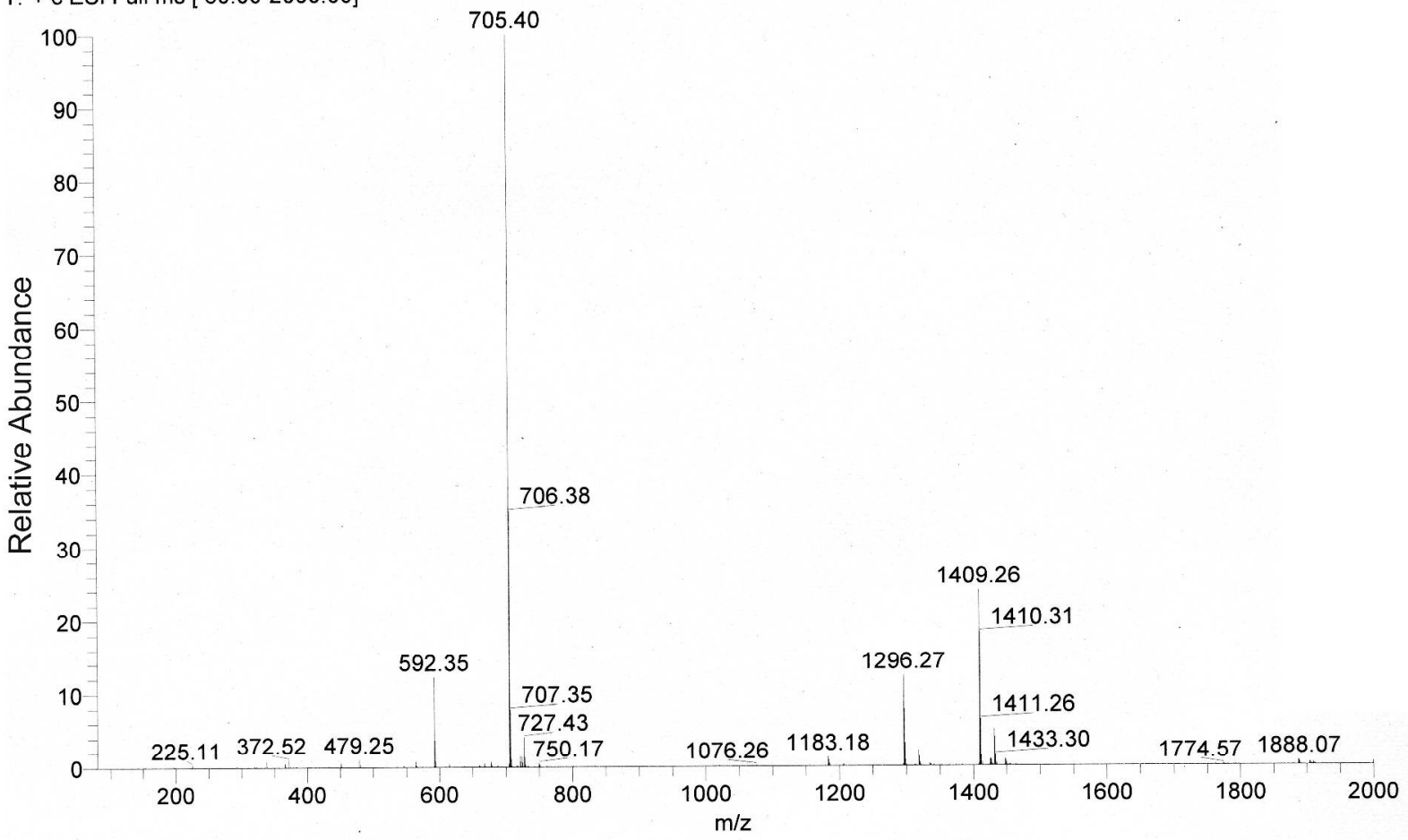

Figure S22. ELSD trace (top) and MS (bottom) of purified hexapeptide monomer 8. 


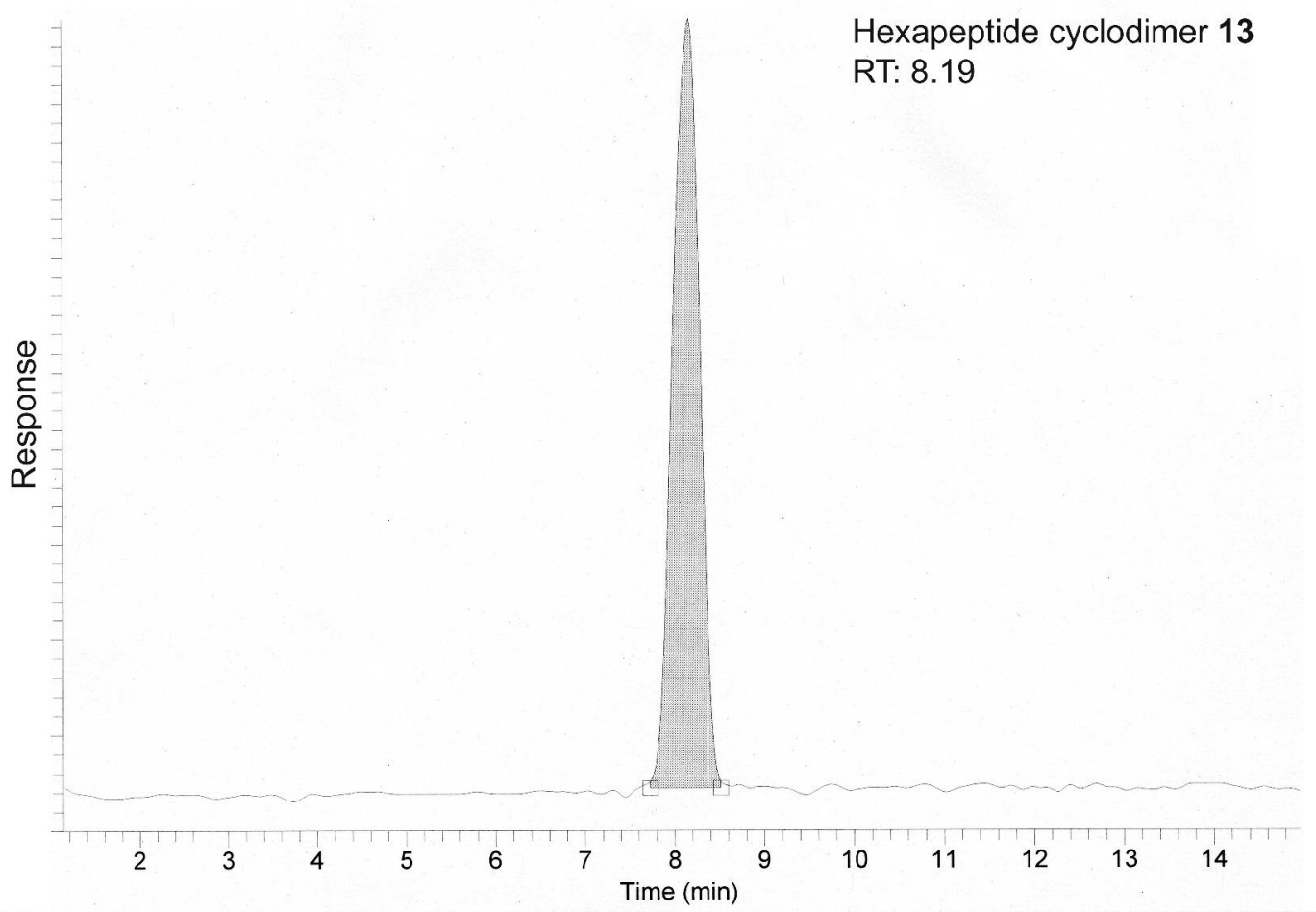

6-dimer-15min \#179 RT: 8.19 AV: 1 NL: $1.09 E 8$ T: + c ESI Full ms [ 180.00-2000.00]

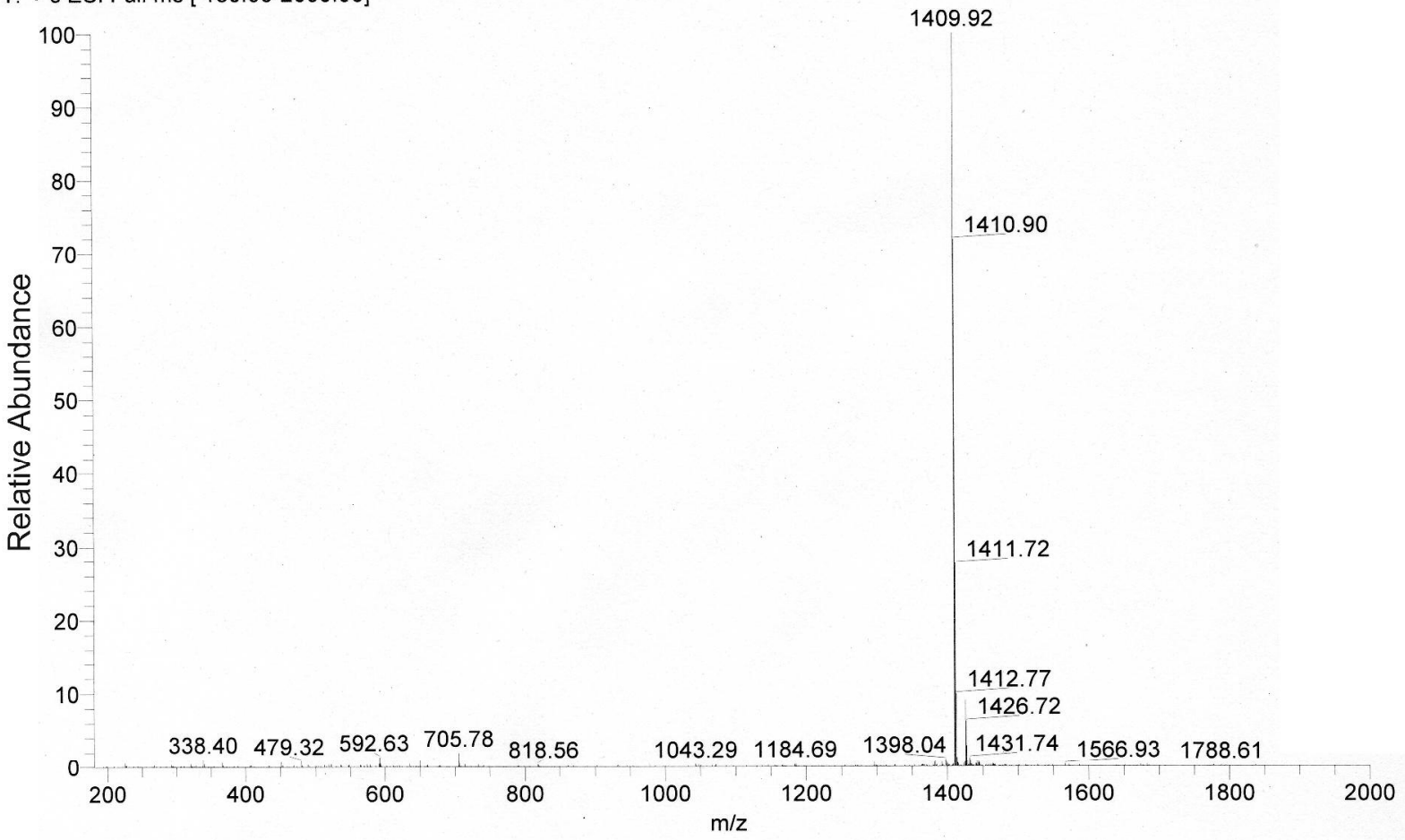

Figure S23. ELSD trace (top) and MS (bottom) of purified hexapeptide cyclodimer 13. 

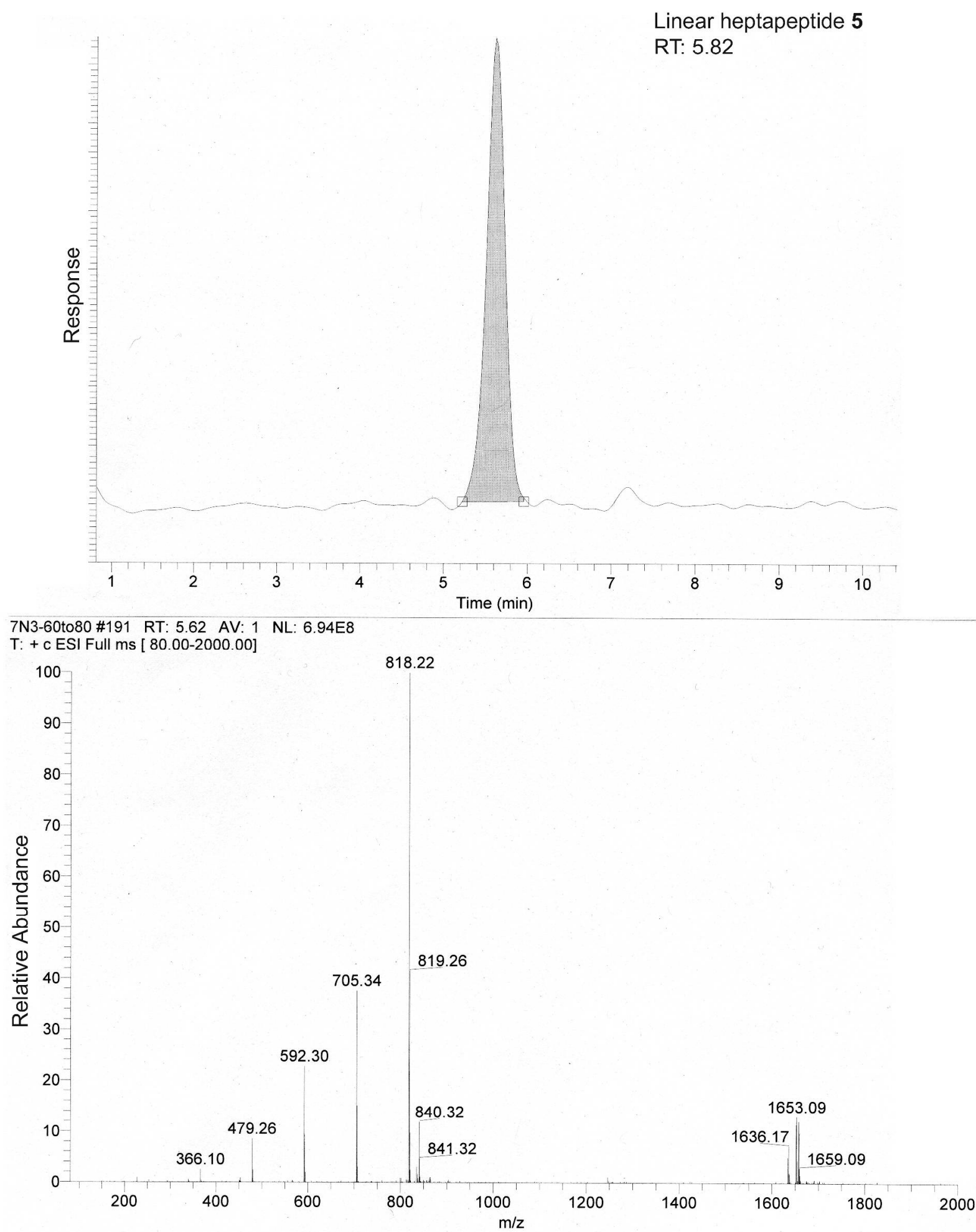

Figure S24. ELSD trace (top) and MS (bottom) of crude linear heptapeptide 5. 


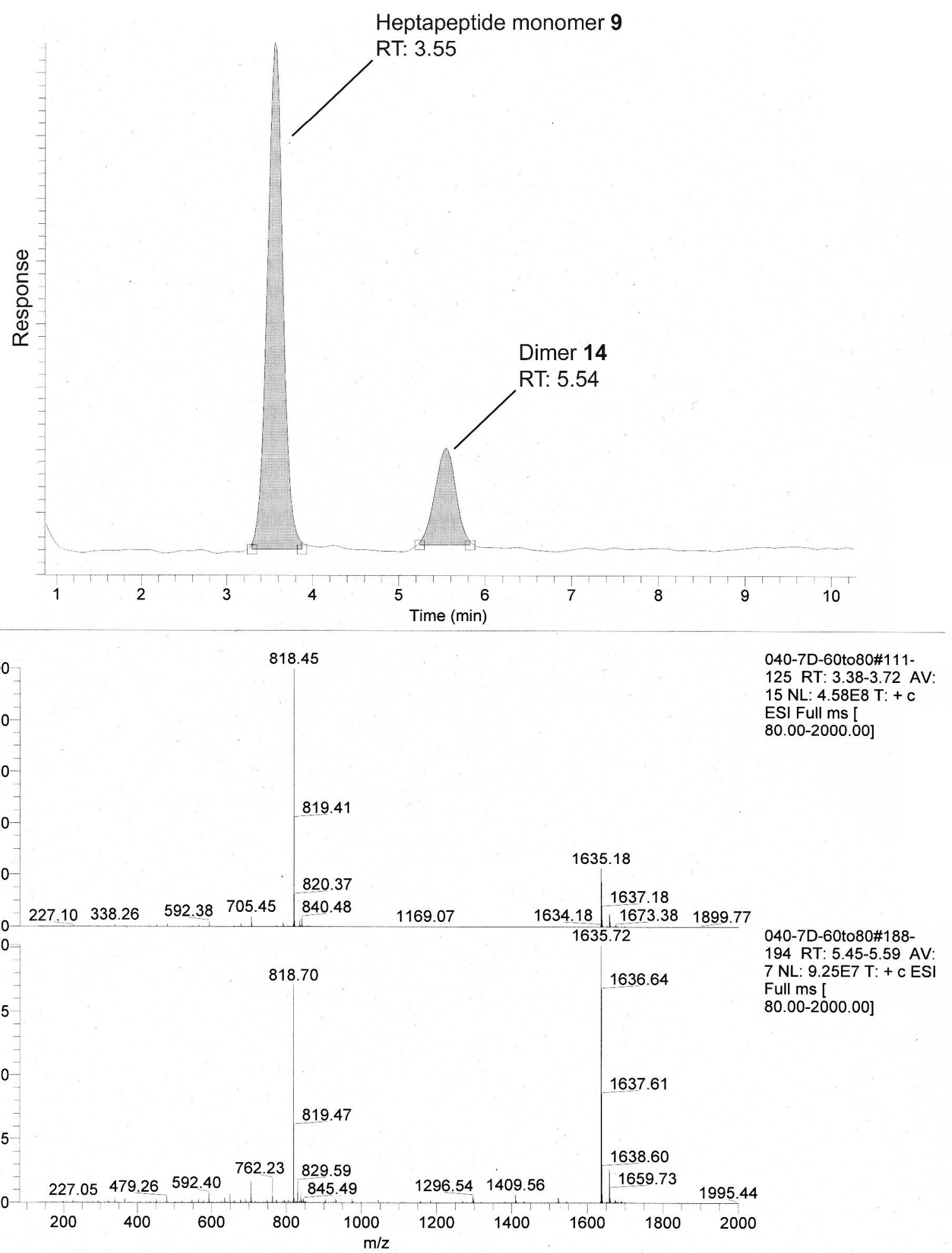

Figure S25. ELSD trace (top) and MS (bottom) of crude reaction mixture for the copper mediated cyclization of heptapeptide 5 , showing cyclomonomer 9 and dimer $\mathbf{1 4}$ products. 


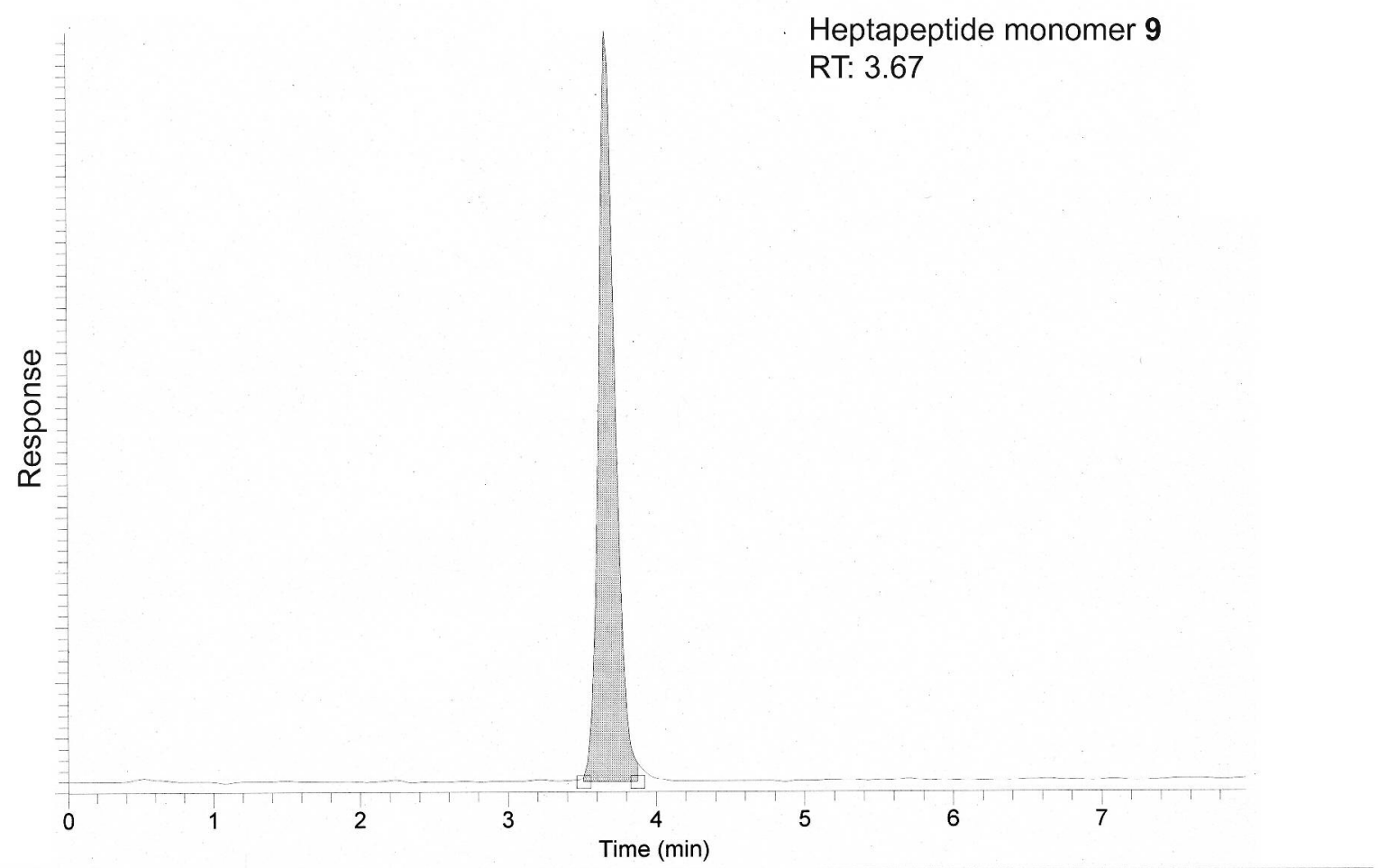

RTII014-7cu-fr17 \#111-123 RT: 3.57-3.85 AV: 13 NL: 5.41E8

$\mathrm{T}$ : + c ESI Full ms [ 170.00-2000.00]

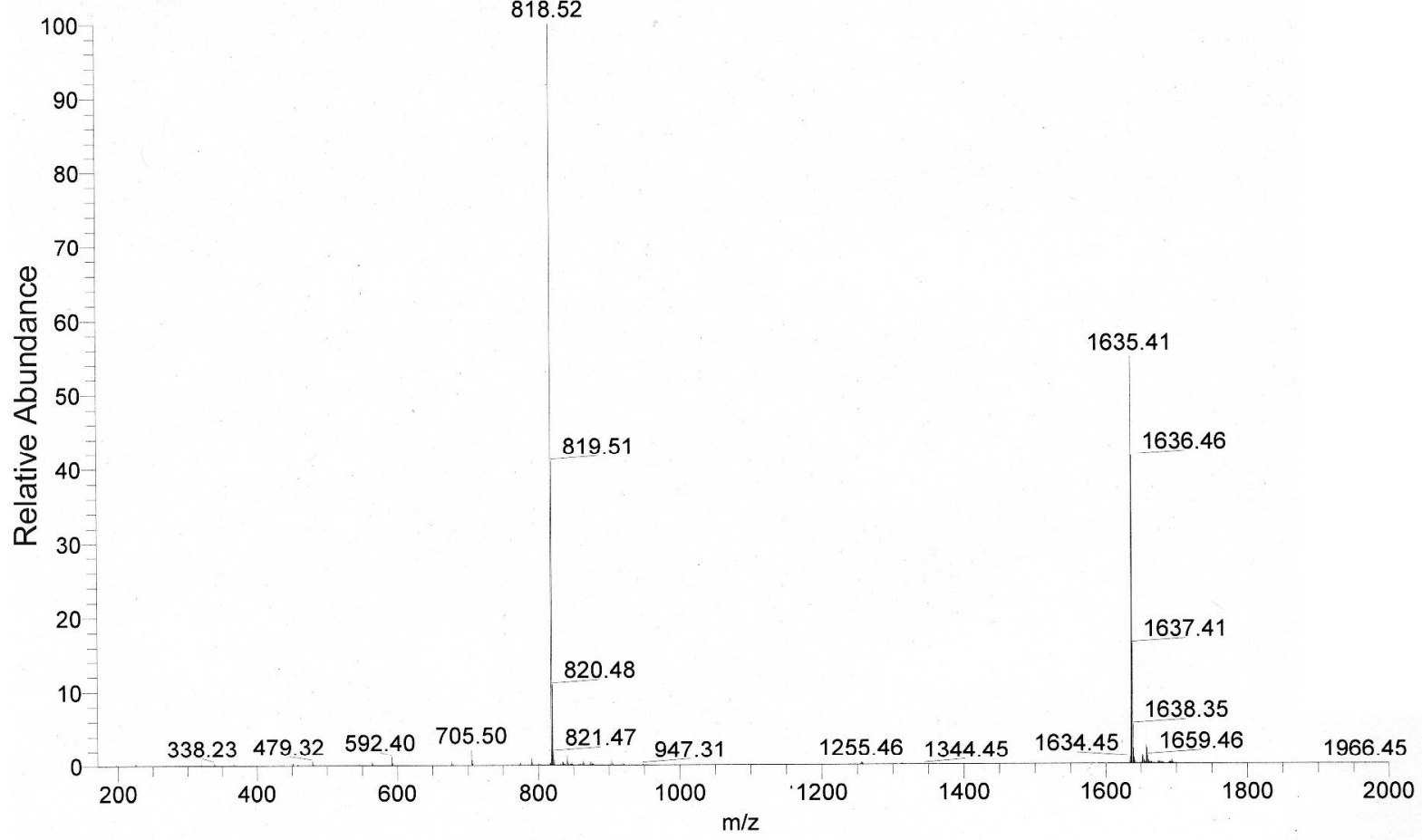

Figure S26. ELSD trace (top) and MS (bottom) of purified heptapeptide monomer 9. 


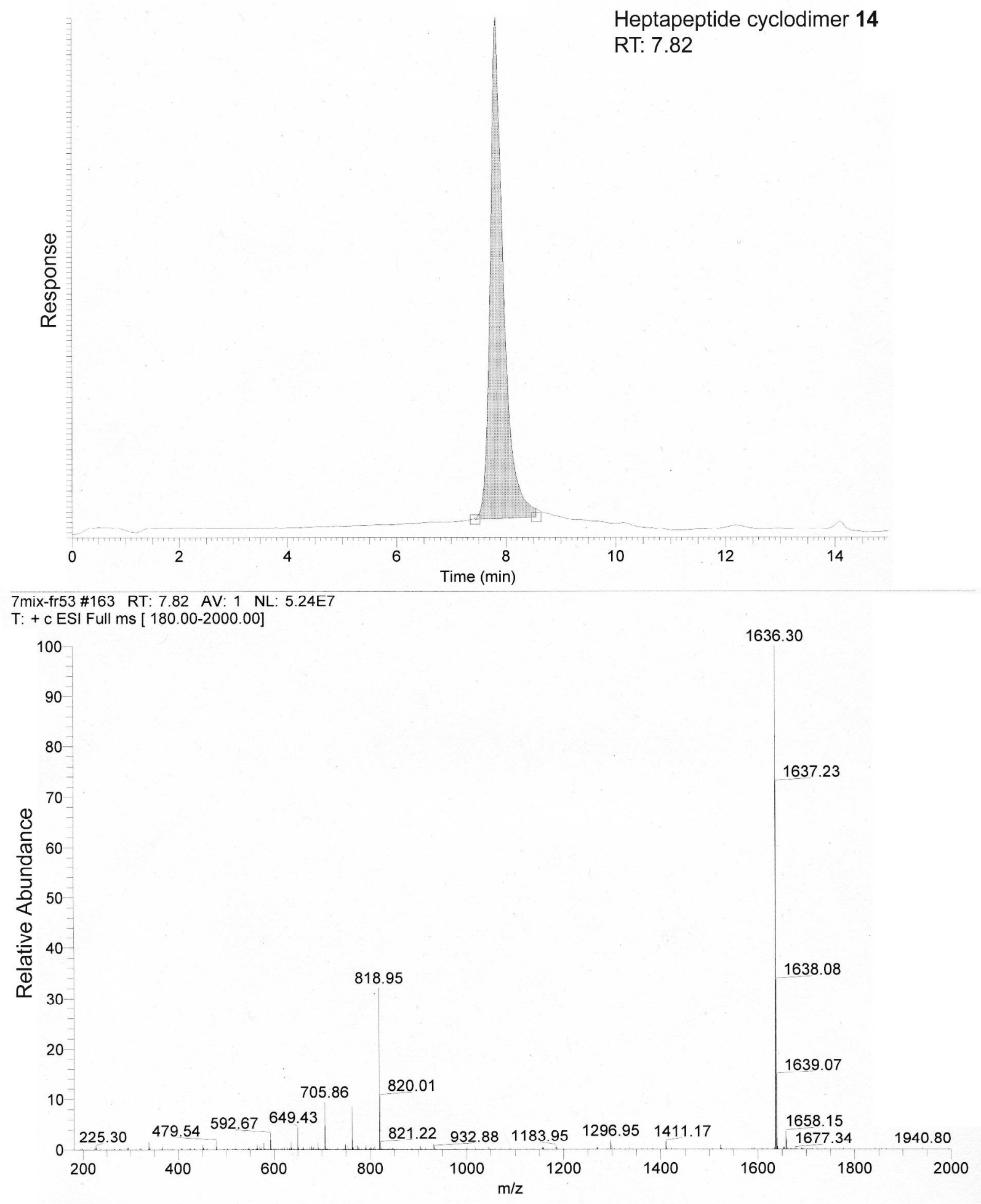

Figure S27. ELSD trace (top) and MS (bottom) of purified heptapeptide cyclodimer 14. 


\section{X-ray crystallography of compound 7.}

A pure sample of 7 was dissolved in DMSO in a test tube, which was placed in a secondary container containing water. The compound crystallized slowly by vapor diffusion.

Crystal data for $\mathrm{C}_{62} \mathrm{H}_{112} \mathrm{~N}_{14} \mathrm{O}_{15} \mathrm{~S}_{2} ; \mathrm{Mr}=1357.78$; monoclinic; space group $\mathrm{P} 2{ }_{1} ; a=13.0384(7)$ $\AA ; b=16.4890(9) \AA ; c=18.3030(10) \AA ; \alpha=90^{\circ} ; \beta=97.5950(10)^{\circ} ; \gamma=90^{\circ} ; \mathrm{V}=3900.4(4) \AA^{3}$; $\mathrm{Z}=2 ; \mathrm{T}=153(2) \mathrm{K} ; \lambda(\mathrm{Mo}-\mathrm{K} \alpha)=0.71073 \AA ; \mu(\mathrm{Mo}-\mathrm{K} \alpha)=0.134 \mathrm{~mm}^{-1} ; \mathrm{d}_{\text {calc }}=1.156 ; 40117$ reflections collected; 19025 unique $\left(\mathrm{R}_{\text {int }}=0.0240\right)$; giving $\mathrm{R}_{1}=0.0490, \mathrm{wR}_{2}=0.1275$ for 16264 data with $[\mathrm{I}>2 \sigma(\mathrm{I})]$ and $\mathrm{R}_{1}=0.0592, \mathrm{wR}_{2}=0.1351$ for all 19025 data. Residual electron density $\left(\mathrm{e}^{-} . \AA^{-3}\right) \mathrm{max} / \mathrm{min}: 1.163 /-0.579$. An arbitrary sphere of data were collected on a colorless platelike crystal, having approximate dimensions of $0.37 \times 0.32 \times 0.09 \mathrm{~mm}$, on a Bruker APEX-II diffractometer using a combination of $\omega$ - and $\varphi$-scans of $0.3^{\circ}$. Data were corrected for absorption and polarization effects and analyzed for space group determination. The structure was solved by direct methods and expanded routinely. The model was refined by full-matrix least-squares analysis of $\mathrm{F}^{2}$ against all reflections. All non-hydrogen atoms were refined with anisotropic thermal displacement parameters. Unless otherwise noted, hydrogen atoms were included in calculated positions. Thermal parameters for the hydrogens were tied to the isotropic thermal parameter of the atom to which they are bonded (1.5 X for methyl, 1.2 for all others). Complete coordinates available upon request.
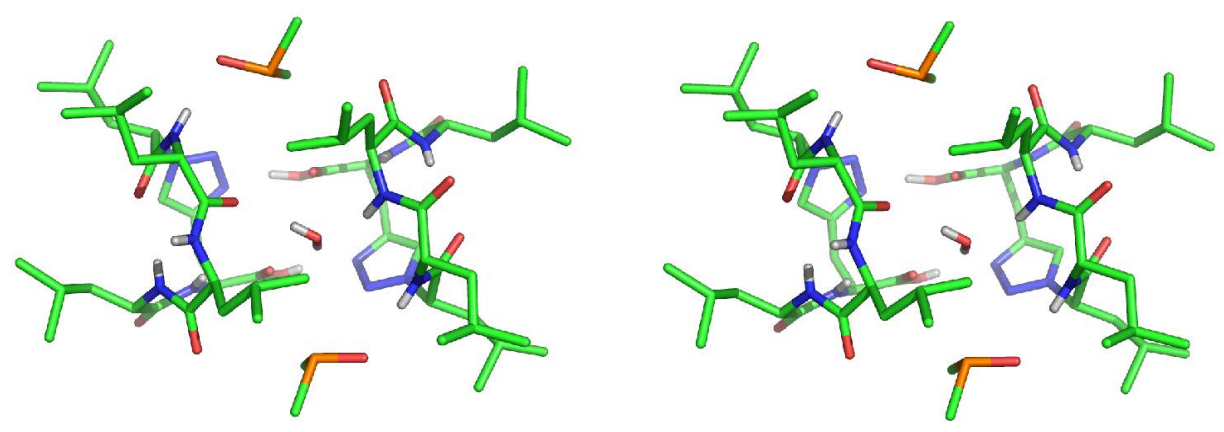

Above: Stereoscopic view of the asymmetric unit of the crystal structure of 7 .

\section{References:}

(1) Lundquist, J. T. t.; Pelletier, J. C. Org. Lett. 2001, 3, 781-783.

(2) Kay, C.; Lorthioir, O. E.; Parr, N. J.; Congreve, M.; McKeown, S. C.; Scicinski, J. J.; Ley, S. V. Biotechnol. Bioeng. 2000, 71, 110-118. 